\title{
A Study of Thermal Degradation and Fire Behaviour of Polymer Composites and Their Gaseous Emission Assessment
}

\author{
Raphael Ogabi *(D), Brady Manescau, Khaled Chetehouna and Nicolas Gascoin \\ INSA Center Val de Loire, University Orléans, PRISME EA 4229, 18022 Bourges, France; \\ brady.manescau@insa-cvl.fr (B.M.); khaled.chetehouna@insa-cvl.fr (K.C.); nicolas.gascoin@insa-cvl.fr (N.G.) \\ * Correspondence: raphael.ogabi@insa-cvl.fr
}

Citation: Ogabi, R.; Manescau, B.; Chetehouna, K.; Gascoin, N. A Study of Thermal Degradation and Fire Behaviour of Polymer Composites and Their Gaseous Emission Assessment. Energies 2021, 14, 7070. https://doi.org/10.3390/en14217070

Academic Editor: Carlos

Miguel Costa

Received: 1 October 2021

Accepted: 22 October 2021

Published: 28 October 2021

Publisher's Note: MDPI stays neutral with regard to jurisdictional claims in published maps and institutional affiliations.

Copyright: (c) 2021 by the authors. Licensee MDPI, Basel, Switzerland. This article is an open access article distributed under the terms and conditions of the Creative Commons Attribution (CC BY) license (https:// creativecommons.org/licenses/by/ $4.0 /)$.

\begin{abstract}
The use of polymer composite materials in the aeronautics and automotive sectors has increased dramatically, and their fire behaviour has become a critical parameter in terms of fire safety. On this premise, it is critical to demonstrate that these composite materials constitute elements whose safety justifies a high level of confidence. This is based on their combustibility and the rate at which flammable and toxic gaseous species are emitted. Thus, strict fire safety regulations are enforced by the relevant authorities concerned because of their potential fire risk. This study analysed papers published between 1970 and 2021 that described the devices used to characterise the thermal behaviour of composite materials at various scales. The objective was to highlight the thermophysical phenomena, making it possible to accurately assess the flammability and thermal stability of polymer composite materials. The results of this research reveal that the small-scale facilities provide detailed understanding and mastery of the thermal reaction properties of the composites. While with the medium scale, the extended fire reaction parameters, which are the key indicators of the fire safety performance, can be determined. On a large scale, the tests were carried out using devices such as the NexGen burner recommended by the FAA. Therefore, with such assays, it is possible to assess the rates of thermal degradation as well as quantified pyrolysis gases. However, compared to other scales, there were very few works on a large scale. In addition, by focusing on the polluting nature of synthetic composite materials, there is also few research studies aimed at designing new polymer composite materials from biological sources.
\end{abstract}

Keywords: composites; fire behaviour; thermal decomposition; thermal gravimetric analysis (TGA); cone calorimeter; next generation burner (NexGen); aircrafts

\section{Introduction}

Over the last decades, polymer composites have shown considerable potential in a wide range of applications. They serve as vital structural components, particularly in the transport and construction sectors such as aircrafts, automobiles, rails, construction, furniture, etc.

In comparison to metal alloys, the properties of these composite materials constitute an effective and viable alternative. Their advantages stem from the fact that they are light, robust, have a high specific resistance, and are corrosion resistant [1,2].

In addition to these characteristics, the latter has a cheap implementation cost. Composite materials, on the other hand, have disadvantages in terms of fire safety due to their high flammability. When composites are heated above the glass transition temperature (Tg) of the polymer matrix (typically above $300-400{ }^{\circ} \mathrm{C}$ ), pyrolysis gas is released as a result of heat degradation. These materials deform as a result of structural failure due to stiffness and creep resistance losses. When examining a fire scenario in this way, the polymer resins released will produce a smoke (mixture of unburned gases), highlighting an environment that is hazardous to human health and property due to its toxicity and flammability [2-5].

Furthermore, given the growing use of composite materials in industry, it is critical to provide components of knowledge about their design. 
On the basis of fire safety regulations, scientific study and certification tests are carried out in this context. This approach entails careful consideration and rigorous efforts in order to develop long-term solutions that lower the risk of fire while retaining composite material mechanical integrity [6,7].

Over the years, researchers have made several attempts to come up with solutions to the problems associated with the use of polymer composite materials. The most successful attempt reported in the literature is the strategy of incorporating a novel chemical substance known as a fire retardant into the polymer matrix to suppress fire (heat release and temperature) and minimise the gas emission species that could be a source of toxicity via the mechanism of the solid phase and gaseous phase phenomena $[4,8-10]$.

The aim of this review is to carry out an extensive study on the various classes of thermal/fire facilities used for the characterisation of polymer composite materials and to examine different test parameters with respect to their gaseous emission properties. This will be achieved via the following specific objectives:

- Collection of data from top five publishers;

- Classification of thermal and fire testing facilities;

- Evaluation of various thermal/fire parameters of polymer composites;

- Gas emission assessment of some composite materials.

Therefore, this document allowed data to be collected from the databases of Elsevier, Springer, Wiley, Sage, and Taylor \& Francis in order to comprehensively study and evaluate the research trend of scientists and engineers as well as to identify the research gap currently existing in this sector. Moreover, the choice of these five editors was made due to the fact that they represent the best editors in the field of fire behaviour of composite materials and energy-related applications [8-10]. With respect to the characterisation of the fire behaviour of composite materials at different scales, various research works have been carried out over the past five decades. Thus, in order to highlight the various findings directly related to this theme, about 405 articles were downloaded from the database of the five publishers mentioned above using the following choice of keywords:

- Thermal property and gas emission;

- Thermal and mechanical properties; and

- Thermal, mechanical properties, and gas emission.

In the review of works dealing with the thermophysical properties of composite materials on the basis of the previous keywords, it is shown in Figure 1 that there are 37\% (81 articles) that present thermal and gas emissions, $13 \%$ (28 articles) that discuss thermal and mechanical properties, and 8\% (17 articles) that research thermal-mechanical properties and gas emission. In addition, it was also found that $42 \%$ (93 articles) mention thermal properties only. However, due to the focus of this work, just the first three keywords were chosen. Therefore, it is clearly shown that among the main group of keywords considered, the thermal properties and gas emission presents the greatest prospects for exploration due to the highest number of articles (81) published in that domain.

In connection with the three previous themes, the following sections will attempt to provide more details on the phenomena that are studied in the context of the characterisation of the thermophysical properties of composite materials. 


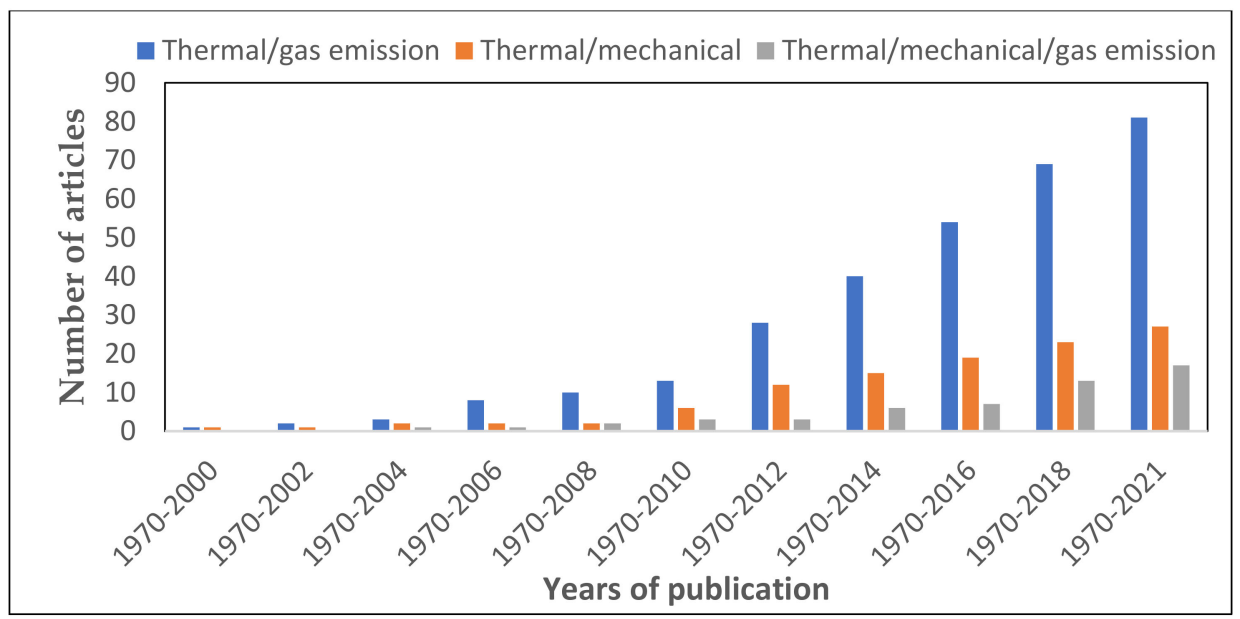

Figure 1. Number of articles obtained based on three keywords from five publishers from 1970 to 2021.

\subsection{Fire Behaviour and Flammability of Polymer Composites}

The process in which a polymer chain is broken down as a result of heating is known as pyrolysis [11].

$$
\text { Biomass(s) } \rightarrow \text { Pyrozylate(g) }+ \text { Char(s) }
$$

However, there are two main types of pyrolysis: namely, smouldering pyrolysis and flaming pyrolysis.

- Smouldering (heterogenous oxidation): This is the process of pyrolysis that is accompanied by the reaction of char oxidation with the release of $2-10 \mathrm{~kW} / \mathrm{m}^{2}$ heat rate.

$$
\begin{gathered}
\text { Biomass }(\mathrm{s}) \rightarrow \text { Pyrozylate }(\mathrm{g})+\text { Char(s) } \\
\text { Char }+\mathrm{O}_{2} \rightarrow \text { Pyrozylate }+\mathrm{CO}_{2}+\mathrm{H}_{2} \mathrm{O}+\text { Emission }+ \text { Ash }
\end{gathered}
$$

- Flaming (homogenous oxidation): Flaming is the process of pyrolysis that is followed by pyrozylate oxidation with the heat release rate value above $10 \mathrm{~kW} / \mathrm{m}^{2}$.

$$
\begin{gathered}
\text { Biomass(s) } \rightarrow \text { Pyrozylate(g) }+ \text { Char(s) } \\
\text { Pyrozylate }+\mathrm{O}_{2} \rightarrow \mathrm{CO}_{2}+\mathrm{H}_{2} \mathrm{O}+\text { Emission }
\end{gathered}
$$

When a polymer material is subjected to a heating source of a minimum heat flux large enough to overcome its activation barrier, the polymer resin and fibre will decompose via bond cleavage, thereby producing carbonaceous char, volatile emissions, and smoke (soot particles), as shown in the chemical reactions above [2,11].

The volatile species consist of gases and vapours that can be either flammable (CO, $\mathrm{CH}_{4}$, low molecular weight organic compounds) or non-flammable $\left(\mathrm{CO}_{2}, \mathrm{H}_{2} \mathrm{O}, \mathrm{NH}_{3}\right)$ so that the process of the fire triangle is self-sustaining (as shown in Figure 2) [12,13]. It is essential that the composite material is supplied with sufficient heat to release the flammable pyrozylate gases, which then react with the atmospheric oxygen to produce $\mathrm{H}^{*}$ and $\mathrm{OH}^{*}$ radicals. These free reactive radicals play a vital role in the chain scission reaction, which leads to the thermal degradation of the polymer composites and sustained combustion [14]. 


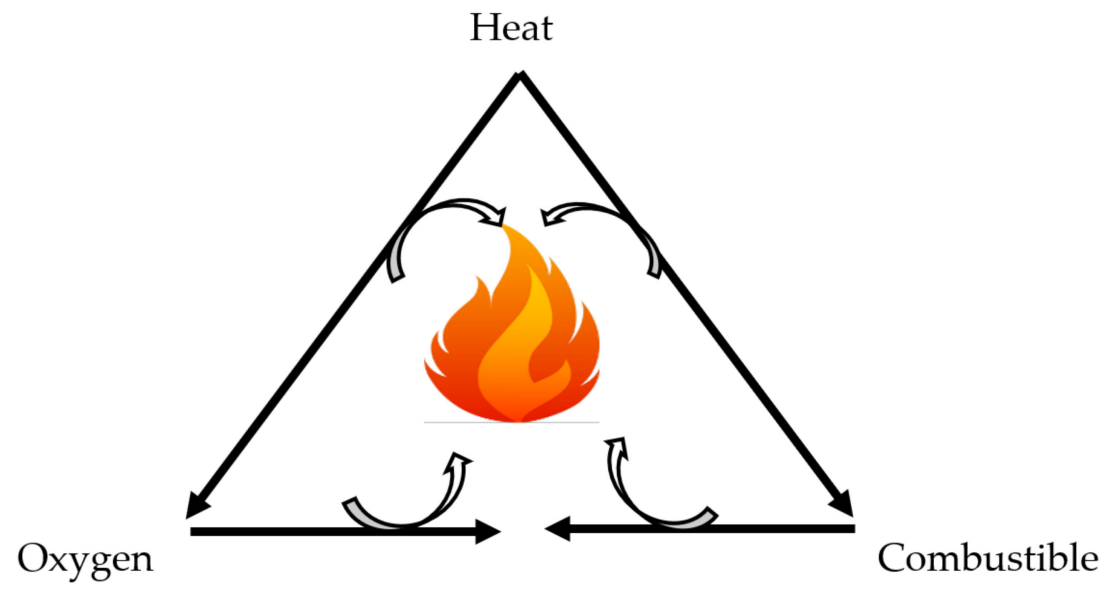

Figure 2. The fire triangle.

\subsubsection{Characteristics of Fire Behaviour of Composites}

The composite materials' fire behaviour can be explained in two ways. First, in terms of 'fire reaction' and 'fire resistance' [6,13]. Even after the actual source of fuel has been suppressed or put out, polymer composites are potential sources of hydrocarbon fuel that cause flame propagation $[13,14]$.

Thus, when exposed to fire, they undergo thermal decomposition process as a result of several sequence of chemical reactions [15-19]. Basically, this decomposition process shows that high-molecular weight polymer chains are broken down into lower-molecular weight volatiles that permeate into the flame zone (as revealed in Figure 3) $[4,8,20]$.

Most polymeric resins and fibres in composite materials degrade by a random chain scission i.e., breakdown of long polymer chain of the lowest-energy bond into smaller fragments.

Other processes in which polymer resins can degrade are end-chain scission (decomposition initiated from the chain terminals and then to the length of entire polymer until it is fully decomposed) and depolymerisation (break down of the chains into monomers) [9,21-23].

A typical fully developed impinging fire involves the following stages:

Ignition: This is the first point of the fire development stage in which the fuel origin is initiated to ignite and a sustained flaming combustion is formed.

Growth: At this stage, the temperature of the compartment will continue to rise as the fire grows in as much as there is enough fuel and oxygen in the system. In addition, the initial propagation of the fire has little or no significant influence on the combustible material. However, if the flame temperature exceeds $350-500{ }^{\circ} \mathrm{C}$, the exposed composite materials will then ignite (acting as an additional fuel source).

Flashover: The flashover point usually occurs at a temperature above $600{ }^{\circ} \mathrm{C}$, and at this stage, all the combustible materials (polymer composites) present in the compartment are fully engulfed by fire.

Fully developed fire: This is usually referred to as the post-flashover point. Basically, the maximum numerical heat release rate value and the flame temperature is attained at this stage. It is characterised by a peak temperature between 900 and $1000{ }^{\circ} \mathrm{C}$, but it can also approach $1200^{\circ} \mathrm{C}$.

Decay: This is the last stage of the fire development process in which the flame temperature of the compartment falls drastically due to the complete consumption of the fuel and combustible material. Moreover, active suppression and extinguishing systems can be employed to be facilitate a fire decay process.

In a fire scenario, some polymer composites can also act as resistant materials, thereby retaining their physical and mechanical characteristics (load-bearing capacity, thermal insulation). However, this action is most effective when chemical additives are incorporated into the polymer resin $[23,24]$. 


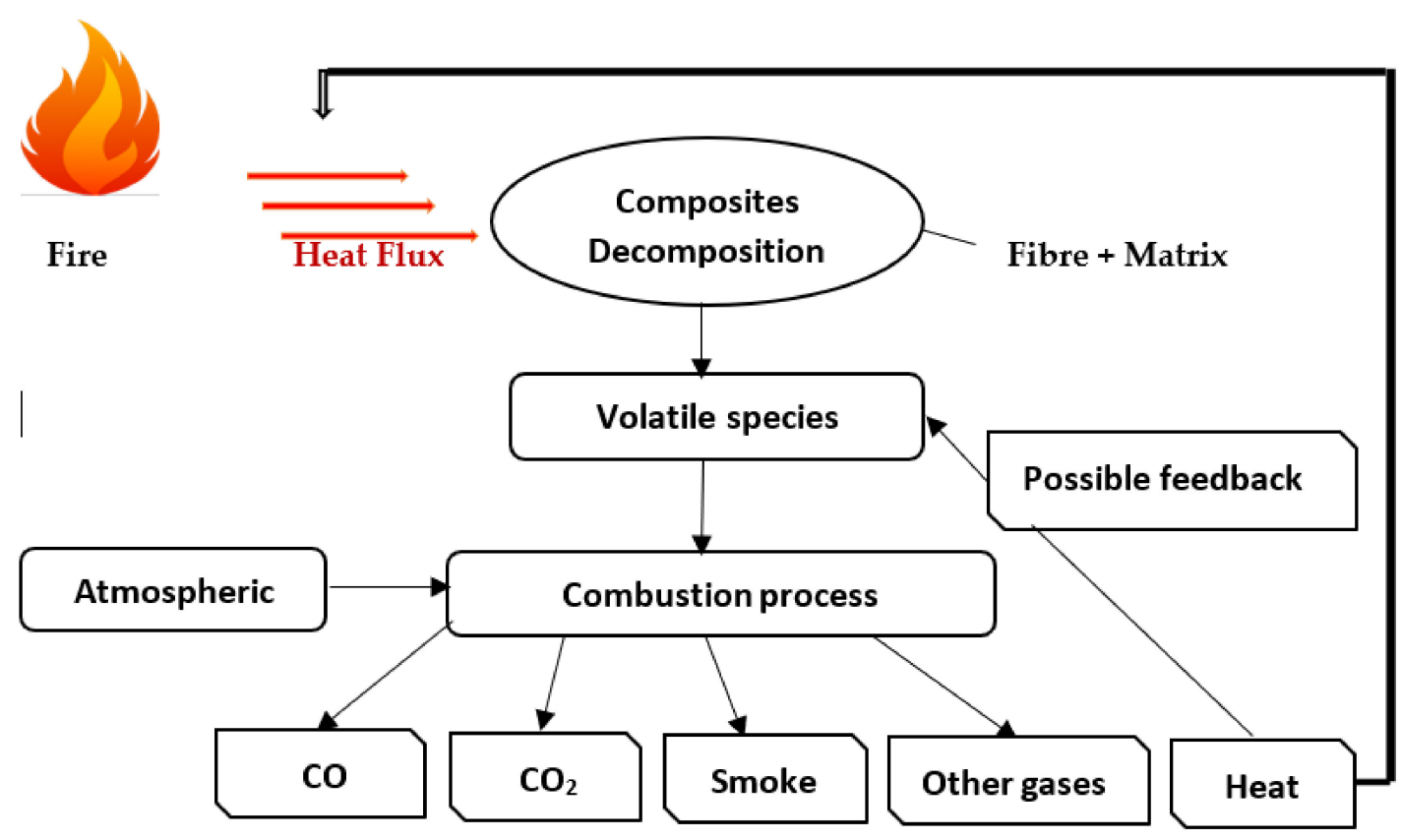

Figure 3. Thermal decomposition cycle of polymer composites.

Biochar is the solid residue left after the early stage of combustion, which is known as carbonisation, charring, devolatilisation, or pyrolysis, when light gases (such as coal gas) and tar are released from a carbonaceous biomass. Pore size distribution, surface chemistry, morphology, crystallinity, and bonding structure are all char characterisation features. Furthermore, the state-of-the-art facilities used for their characterisation are $\mathrm{N}$ and $\mathrm{CO}_{2}$ gas physisorption, $\mathrm{Hg}$ porosimetry, scanning electron microscope/energy-dispersive using X-ray (SEM-EDX), X-ray photoelectron spectroscopy (XPS), scanning electronic microscopy (SEM), X-ray diffraction (XRD), transmission electronic microscopy (TEM), and Raman nuclear magnetic resonance (NMR), respectively.

- Surface Elements:

While an SEM micrograph can reveal a lot about the surface and pore morphology of biochar, it cannot identify the chemical elements that make up the biochar surface on its own. Scanning electron microscopy with energy dispersive X-ray spectroscopy, abbreviated SEM-EDX or just EDX, is utilised to achieve this objective. EDX identifies chemical components on the surface of biochar, allowing for the observation and evaluation of biochar's efficacy as an inorganic contaminant adsorbent [25].

- Surface Chemical Compounds and Functional Groups:

X-ray photoelectron spectroscopy allows for a more exact characterisation of chemicals on a biochar surface (XPS). XPS can study chemical compounds and differentiate between species of the same element [26], as well as various chemical bonds at the surface, in addition to analysing biochar elements at the surface. Differentiating between carbon bonds such as $\mathrm{C}-\mathrm{C}, \mathrm{C}-\mathrm{H}, \mathrm{C}=\mathrm{O}$, and $-\mathrm{COOH}$ bonds, or nitrogen bonds (such as nitrogencarbon bonds, amino acid bonds, and ammonium bonds) are examples $[27,28]$. XPS is particularly effective at characterising biochar surfaces before and after use in applications that deposit diverse chemical compounds on the biochar surface, similar to SEM and EDX, but with more detail.

- Morphology

The morphology of biochar is primarily concerned with the porous features of the biochar at various scales. Optical and scanning electron microscopy are used to investigate it (SEM). The dimension, shape, distribution, arrangement, and interconnectivity of macropores, mesopores, and micropores are all common traits studied. The preservation of precursor material morphology in biochar generated by porous biomass is frequently desired and may be validated by SEM imaging [29]. 
- Crystallinity:

The degree of order present within the biochar structure is referred to as crystallinity. $\mathrm{X}$-ray diffraction (XRD) is a popular method for determining the amount of crystalline carbon in biochar, as well as providing information on chemical constituents including lignocellulosic components [30]. Another approach for determining the crystallinity of biochar is transmission electron microscopy (TEM), which can identify both amorphous carbon and graphite crystals [31].

- Bonding structure/Aromaticity

Many critical features of biochar, such as thermal and chemical stability, are determined by its bonding structure.

The following techniques are used to identify strong bond structures, such as those seen in aromatic compounds, which arise as a result of pyrolysis parameters and charcoal feedstock. Raman spectroscopy can reveal a lot about the bond topologies in biochar structures $[29,30]$.

\subsubsection{Fire Retardancy, Flame Retardants, and Mechanism}

The concept of flame retardancy has to do with the method of enhancing the flameretardant properties of fibre-reinforced polymer composite materials, thereby reducing their flammability and improving their thermal stability $[27,28]$.

The techniques employed vary from the additive compounds simply mixed into a polymer resin or heat-resistant coating to the complex method that involves the chemical modifications of the resin or to heat inducing the composite surface to impact intumescence [29]. The addition of inert fillers (talc, silica) or thermally active fillers (hydrated oxides) to the polymer matrix is a typical strategy for reducing composite flammability [28]. Flame-retardancy mechanisms are mainly classified either as either 'condensed phase' or 'gas phase' phenomena, depending on whether the flame-retardant compound(s) employed disrupt the decomposition of the polymer or the combustion process in the flame [15,31].

The mechanism of the condensed phase involves the processes of diluting the amount of combustible polymeric materials (fuel source) by adding an inert filler (particles), which reduces the temperature that impinges on the composites via the action of heat sink, and by increasing the aromaticity of the matrix in order to decompose a carbonaceous char of an insulating surface layer that inhibits heat absorption into the underlying composites, thus reducing flammable gas emission [7,32-35].

The gas combustion occurs in the solid and (to a little extent) the intermittent flame zone with the release of $\mathrm{H}^{*}$ radical, which combines with atmospheric oxygen present in the flame zone to form hydroxyl radicals $\left(\mathrm{OH}^{*}\right)$ [4].

$$
\begin{gathered}
\mathrm{H}^{*}+\mathrm{O}_{2}^{*} \rightarrow \mathrm{OH}^{*}+\mathrm{O}^{*} \\
\mathrm{O}^{*}+\mathrm{H}^{*} \rightarrow \mathrm{OH}^{*}+\mathrm{H}^{*} \\
\mathrm{H}^{*}+\mathrm{O}_{2}^{*} \rightarrow \mathrm{CO}_{2}^{*}+\mathrm{H}^{*}
\end{gathered}
$$

The major exothermic reaction that produces the main heat in a typical flame is represented in Equation (3) [9].

However, in the gas-phase mechanism, the flame-retardant operates by inhibiting the combustion reaction by decreasing the growth and the amount of heat transferred to the material from the flame zone [36].

This mechanism works in two main ways. First, it works by releasing free radicals (such as halides and phosphates) that terminate the exothermic combustion reaction via the removal of the $\mathrm{H}^{*}$ and $\mathrm{OH}^{*}$ reactive radicals from the flame. Secondly, the gas-phase mechanism lowers the temperature by releasing non-flammable vapours that dilute the concentration of $\mathrm{H}^{*}$ and $\mathrm{OH}^{*}$ gases in the flame [20,24].

Thus, the most effective flame retardants operate in both the condensed and gas phase simultaneously. However, there are lots of flame retardants that function in either the condensed or gas-phase mechanism [37]. 
Flame retardants are broadly classified into two major groups: additive compounds and reactive compounds [38].

The additive flame retardants are well mixed in the polymer resin in the course of processing, but they do not react chemically with the polymer resin.

The following elements are usually contained in the chemical formation of most of these compounds: boron, phosphorus, aluminium, antimony, chlorine, or bromine [38].

Several additives occur as hydrated metal salts that undergo endothermal decomposition when they come in contact with fire and therefore decrease the total heat release rate of a polymer matrix [32,39]. Furthermore, some additives also release water vapour during thermal decomposition that dilutes the concentration of flammable emission gases liberated into the flame zone [11,24].

However, the reactive fire retardants are integrated into the molecular network of the polymer structure by the process of co-polymerisation [40,41]. The reactive compounds are mainly based on halogens (chlorine, bromine), phosphorus, melamine, and inorganic compounds. Among all the reactive flame retardants, the most effective is the halogen source $[18,33-35,42]$. They operate by the release of reactive chloride or bromide radicals into the flame zone that provides the highest level of flammability resistance by disrupting the oxidative combustion reactions of the flammable volatiles $[25,43,44]$. Unfortunately, the halogen-based flame retardants have been prohibited in recent times because of the health and environmental challenges associated with their usage.

Moreover, phosphorus-based compounds are also highly efficient flame retardants that act by decreasing the amount of combustible gases produced from the degrading polymer material by enhancing the production of char.

Thus, for a given polymer composite, the choice of an appropriate flame retardant depends on many factors such as cost consideration, the decomposition of temperature of the fire retardant, weight, and most importantly, the compatibility between the host polymer material and the flame-retardant compound. Furthermore, in other to improve the adverse effect of decreased mechanical properties of some filler additives, it is therefore necessary to carry out surface treatment of the particles to enhance the chemical interaction with the polymer resin. In addition, some filler compounds increase the concentration of smoke particles and poisonous fumes released by the degrading composite material. Therefore, to maximise the flammability resistance while minimising the negative consequence of the mechanical strengths, toxicity, and smoke, it is imperative to adopt the strategy of incorporating the combination of two or more flame retardants into the polymer composite materials (this phenomenon is known as the intumescent fire-retardant system).

\subsection{Fire/Thermal Facilities and Test Conditions}

The experimental methods employed in the evaluation of the composite materials range (in terms of sample size) from bench-top apparatus i.e., small scale for testing coupons with weight of only a few grams up to full-scale tests for large structures with weights in kilograms as shown in Table 1 below.

Table 1. The experimental working scales adopted to investigate the thermal decomposition of composites.

\begin{tabular}{|c|c|c|}
\hline Scales & Sample Dimensions & Thermal Decomposition Conditions \\
\hline Small & $\mathrm{mm}, \mathrm{mg}$ & Size: $2-5 \mathrm{mg}, \mathrm{HRR}^{\mathrm{a}}$ : 0-110 kW/ $\mathrm{m}^{2}$ \\
\hline Medium & $\mathrm{cm}, \mathrm{g}$ & Size: $100 \times 100 \mathrm{~mm}$, thickness: $3-50 \mathrm{~mm}$ HRR: $0-110 \mathrm{~kW} / \mathrm{m}^{2}$ \\
\hline Large & $\mathrm{m}, \mathrm{kg}$ & $\begin{array}{c}\text { Size: } 500 \times 500 \mathrm{~mm} \text {, thickness: } 3-100 \mathrm{~mm}, \mathrm{HRR}: 116-300 \mathrm{~kW} / \mathrm{m}^{2} \text {, } \\
\text { Flame temperature: } 1100-1200^{\circ} \mathrm{C}\end{array}$ \\
\hline
\end{tabular}

${ }^{\mathrm{a}}$ HRR: heat release rate.

Each scale allows the evaluation of some certain phenomena. However, it is important to state that there is no one single testing technique that can evaluate all the reaction and resistance properties of a composite for all the several fire scenarios [45]. 
However, a broad spectrum of techniques is available with each method relating to a specific type of fire hazard. In addition, the most important fire reaction property that evaluates the fire hazard potential of a composite is the heat release rate [46,47]. The fire property of heat release ranges from low-intensity fires (where the radiant heat flux is under $20 \mathrm{~kW} / \mathrm{m}^{2}$ ) to intense fires (with the heat flux exceeding $150 \mathrm{~kW} / \mathrm{m}^{2}$ ) [48-50].

The major advantages of the bench-scale apparatus (small and medium) are as follows: they are cheap, fast, easier to understand regarding the test parameters and fire chemistry, and they usually provide consistent and replicable data that could be used to validate numerical models for the prediction of the fire behaviour of composite materials in large fires [40,51]. The main disadvantage of most bench-scale tests (i.e., those used to measure the HRR and SPR) is that they do not consider the effects due to fire growth. In addition, it is almost impossible to simulate the actual fire end-use conditions. For instance, the heat release rate and the air movements and the oxygen/fuel ratio involved in the actual fire are always in contrast with those in the bench-scale fire tests. Consequently, this can affect the measured fire behaviour properties [52,53].

Regardless of the scale used, it is vital to ensure that the fire reaction tests are carried out in conditions that precisely reproduce the type of fire in which the composite materials will be subjected.

\section{Methodology}

There has been an increase in the research interest displayed in the research domain of 'thermal and gaseous emission' of composite materials over the last 5 decades (as shown in Figure 1). Therefore, this review is aimed at conducting a detailed study of the various classes of thermal facilities, their techniques and test conditions with respect to both the qualitative and quantification examination of gas/volatile emissions of the polymer composite materials under a combustion process.

\subsection{Fire Behaviour Test Facilities}

The fire behaviour of polymer composite materials can be studied using three main classes of test facilities as grouped below in Figure 4.

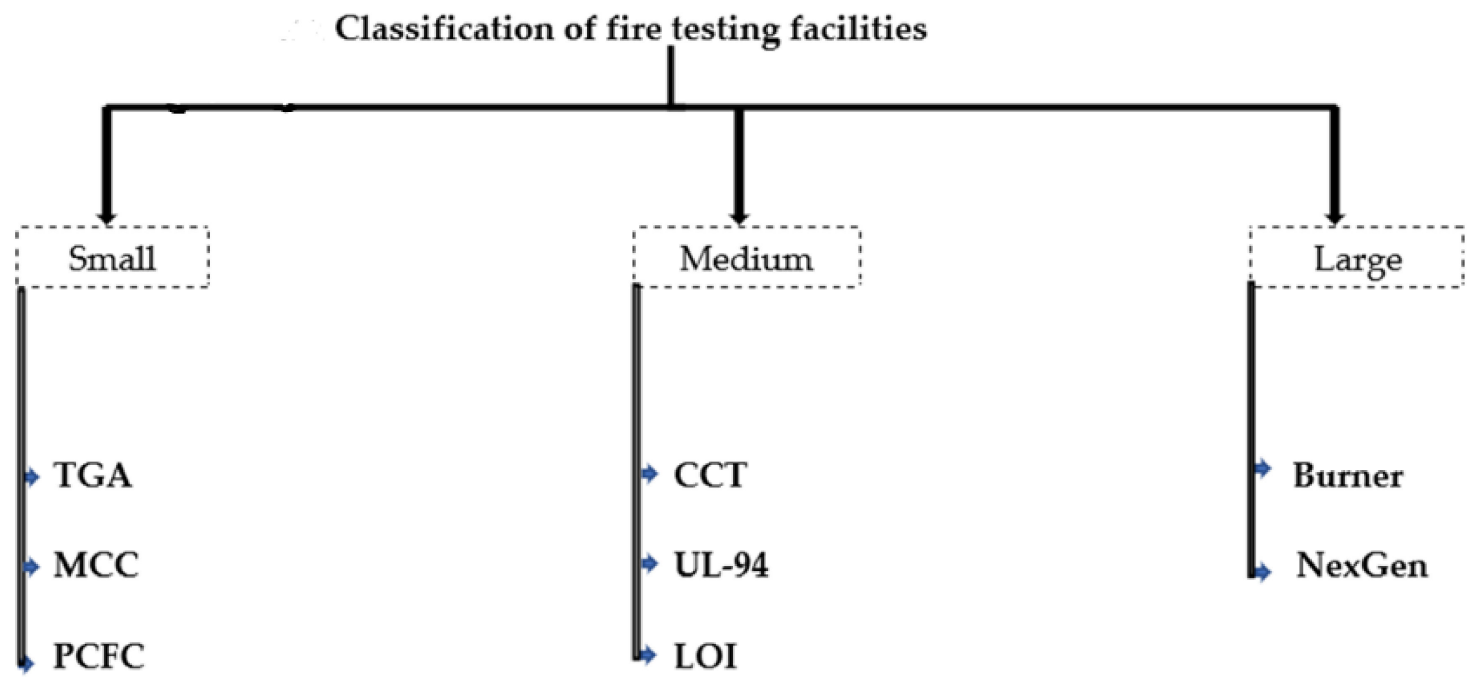

Figure 4. The classification of facilities based on different scales.

The Figure 5 below showed the plot of the number of articles obtained based on the scales of classification of the various thermal flammability test facilities that could be used in the study of the combustibility and thermal stability of polymer composite materials. 


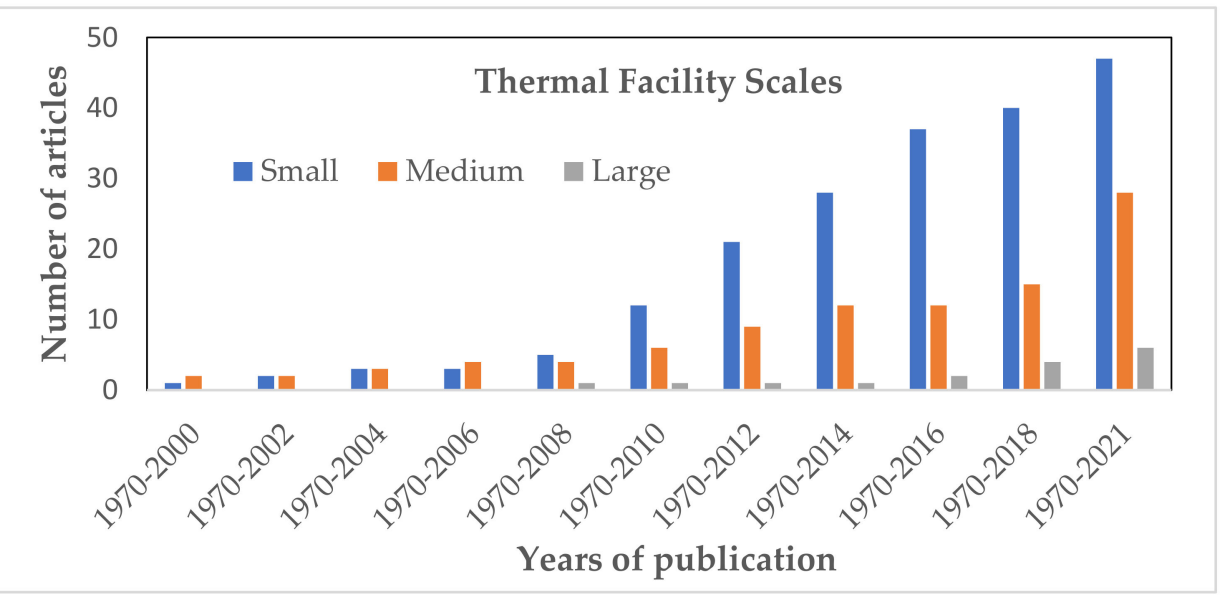

Figure 5. Number of articles published on thermal and gas emission keywords.

It can be observed from the trend of results (ranging from 1970 to 2021) that 47 articles (58\%) were committed to the use of small-scale facilities, while 28 articles $(35 \%)$ and 6 articles $(7 \%)$ involved the utilisation of medium and large scales, respectively.

Thus, it is evident that more research effort is needed in this scientific domain in order to provide a new perspective and better understanding on the fire reaction properties of the large-scale burners, which represent the realistic combustion scenario for the polymer composites during application.

\subsubsection{Thermalgravimetric Analysis}

TGA is a small-scale facility in which a very small sample (a few millimetres and milligrams) under investigation is degraded in different atmospheres (usually in air and inert gas) at different heating rates usually between 2 and $20^{\circ} \mathrm{C} / \mathrm{mins}$ [54].

The major advantage of this device is that the conditions of heating rate, the temperature, the atmosphere, and the heat transfer phenomena are usually mastered and controlled.

The hypothesis associated with the test in this device is similar to that of the DSC (differential calorimetric analysis). They are both used to determine the cure behaviour and glass transition temperature ( $\mathrm{Tg}$ ) of polymer composite materials [55].

\subsubsection{Microscale Cone Calorimeter}

The MCC is used to measure the thermal combustion properties of polymer composites. For instance, ASTM D7309-07 involves the following methodology.

Each sample (4-8 mg) will be heated at $1{ }^{\circ} \mathrm{C} / \mathrm{s}$ from 90 to $600{ }^{\circ} \mathrm{C}$ for $30 \mathrm{~s}$. During decomposition, the pyrozylate products are usually transferred in the nitrogen atmosphere to a combustion furnace of high temperature where pure oxygen is added, and the pyrolysis products are fully combusted [54]. Then, the heat release rate is calculated from the concentration of the oxygen that is measured with the help of an oxygen analyser $[9,56]$.

\subsubsection{Pyrolysis Combustion Flow Calorimetry}

The PCFC is a technique developed by Lyon and Walter that is used to investigate the fire behaviour of materials (polymer composites) at the microscopic scale level. First, samples of $2 \mathrm{mg}$ weight are pyrolysed at $1{ }^{\circ} \mathrm{C}$, and the pyrolysed products are transferred via an inert gas flux.

Then, they are mixed with oxygen gas before entering into a combustor at $900{ }^{\circ} \mathrm{C}$, where the products are totally oxidised. Then, the HRR is measured as a function of temperature $[18,20]$. 


\subsubsection{Cone Calorimeter}

The cone calorimeter testing technique is the most frequently and reliable used method of assessing the thermal decomposition and fire performance index of polymer composite materials. The cone calorimeter (ISO standard of 5660-1) is considered as the most significant fire testing instrument for the solid materials. Most fuel generated 13.1 MJ of energy per $1 \mathrm{~kg}$ of oxygen consumed during combustion. The preset heat flux of $50 \mathrm{~kW} / \mathrm{m}^{2}$ is often used to test some parts of the aircraft materials [57-59].

\subsubsection{Limiting Oxygen Index}

The LOI technique is based on the United States and European test standards such as the ASTM D2863, ISO 4589-2 [12,59]. The limiting oxygen index is used to measure the minimum concentration of oxygen present in the oxygen-nitrogen atmosphere that is needed to support the ignition and flaming combustion of vertically mounted composite materials. According to the ASTM D2863-97, the sample size specification is $100 \mathrm{~mm} \times$ $6.5 \mathrm{~mm} \times 3.2 \mathrm{~mm}[54,60]$.

\subsubsection{Underwriters' Laboratories 94 (UL-94)}

For the vertical fire test, there are three ratings: V-0, V-1, and V-2. If the total flame time is less than $10 \mathrm{~s}$, the sample is ascribed a V-0 rating. When the total flame time is between 10 and $30 \mathrm{~s}$ and the cotton material under the sample is not ignited, the sample is assigned a V-1 rating. However, if the cotton material is set ablaze during the test, then the composite sample will be rated V-2. Among all the ratings, V-0 represents the best performance $[29,61]$.

\subsubsection{Next Generation (NexGen) Burner}

The next generation burner is a large-scale facility devised by the Federal Aviation Administration (FAA). The impinging flame condition must ensure a heat flux of $116 \mathrm{~kW} / \mathrm{m}^{2}$ $\pm 10 \mathrm{~kW} / \mathrm{m}^{2}$ and an average temperature of $1100{ }^{\circ} \mathrm{C} \pm 80^{\circ} \mathrm{C}$ [61]. This test bench is designed to represent a fire condition that is close to the realistic end-use applications that the decomposing composite materials will encounter in real life. In addition, the test samples must withstand a fire exposition to a kerosene-air premixed flame without self-ignition at the exposed surface areas for at least $5 \mathrm{~min}$, after which it is certified as fire-resistant; at $15 \mathrm{~min}$, it is certified as a fire-proof material $[5,62,63]$.

\subsection{Fire Behaviour and Hazard Parameters}

Fire hazard is a concept that measures the potential of a composite material to cause fire harm. It could also be defined as the probability of fire occurrence and its consequences. There are several indicators or determinants of the fire hazard behaviour of polymer composite materials, these include the heat release rate, ignitability, flame spread, smoke toxicity, etc.

However, the importance of the heat release rate as a measure of fire hazard supersedes other fire reaction properties.

Some of the commonly measured fire properties are discussed below:

HRR: The heat release rate is the measure of the quantitative amount of the heat energy released by a composite material per unit area with a unit of $\mathrm{kW} / \mathrm{m}^{2}$. The peak of heat release (pHRR) is related to the onset of the flashover in a real fire scenario. This parameter is not a 'physical property' of the fuel, but it strongly depends on its reaction under certain condition. Therefore, it is not measured directly but can be deduced indirectly from other direct measurements. The chemical method of measurement of the heat release rate is the 'oxygen consumption calorimetry' [15].

According to the standard calorimeter (ISO 5660), the HRR is calculated using Jassen's work. The HRR of a fire reaction measurement is regarded as the best indicator of the fire hazard property of polymer composite materials $[1,6]$ 
TTI: The time-to-ignition is defined as the period in which a composite material under the radiation of heat flux can resist flammability before ignition; i.e., it is a measure of the flammability resistance of a composite material under flaming combustion [6].

FIGRA: The fire safety performance of a composite material is best expressed in terms of its fire growth rate index, which is a measure of the degree of fire hazard of the material exposed to fire. It is the ratio of pHRR to TpHRR. FIGRA shows the burning propensities of materials. Generally, a lower index value indicates delay in the time to ignition, which therefore suggests that there is sufficient time for the evacuation of people in conflagration $[17,24]$.

EHC: The effective heat of combustion is the measure of the quantity of heat emission due to the volatile species released into the flame zone from the decomposing composites material during combustion. This determines the $\mathrm{CO} / \mathrm{CO}_{2}$ ratio [29].

SPR: The smoke production rate can be estimated as the product of the extinction coefficient and the volumetric flow rate of the smoke in the exhaust duct. Meanwhile, the total smoke production is obtained by numerical integration of the smoke production rate (TSP) over the period under consideration. The smoke alongside other toxic gases release is the major reason why deaths occur during fire outbreak. Thus, the investigation of the $\mathrm{SPR}, \mathrm{TSP}$, carbon dioxide production $\left(\mathrm{CO}_{2} \mathrm{P}\right)$, and carbon monoxide production (COP) for fibre-reinforced polymer composites is very crucial in evaluating the potentiality of fire hazards $[29,64]$.

FLAME SPREAD: The flame is the measure of the flame velocity in which the flame front travels over the surface of an impinging composite material exposed to fire. The rate of flame spread is determined experimentally. Therefore, it is test-dependent, and various techniques are used with different configurations [24].

FIRE RESISTANCE: The fire resistance of a composite is the resistance of the material to fire spread, which thereby maintains its mechanical or structural integrity (load capacitybearing property). There are three main fire-resistance properties: heat insulation, burnthrough resistance, and structural integrity [24,65].

Heat insulation describes the rate of heat conduction via a material under fire combustion $[3,22,65]$.

Burn-through is the period of time required for the flame impingement to pierce to the opposing side [5].

Mechanical integrity is defined as the ability of a material to retain its mechanical characteristics such as strength, stiffness, and creep resistance in a flaming combustion, and the flame has been put off $[24,26]$

\subsection{Smoke and Toxic Gases Assessment}

Most passengers who lose their lives in fire accidents are killed due to smoke poisoning by inhaling toxic gases in the smoke rather than from the heat or burn. Further studies have showed that incapacitation and death is due to the $\mathrm{CO}$ that results in most fatalities during or immediately after the fire accident occurrence. Some of the examples of the toxic gases include $\mathrm{HCN}, \mathrm{HCl}$, and other mutagenic compounds (e.g., quinoline) or gases that stimulate acute symptoms such as convulsions or shock (e.g., phenol) [10,47,66,67].

Sadly, there are no models that can accurately predict the combustion gases released from the decomposing composites both qualitatively and quantitatively. Therefore, the smoke toxicity must be determined experimentally.

There are significantly two experimental approaches used in the assessment of smoke toxicity: the analytical chemical method and the animal exposure methods $[68,69]$.

The chemical approach uses Fourier Transform Infrared Spectroscopy (FTIR) and chromatography/mass spectrometry (GC/MS) to determine all the compounds present in the smoke both qualitatively and quantitatively [70].

However, the major challenge with this technique is that it is difficult and time consuming to predict the potency of the toxic species accurately, especially for different fire scenarios. The main reason is because the number of compounds released by the 
composites exposed to the decomposition process is too large (over 100 compounds). In addition, the toxic potency and health effects of many compounds are not known [71-73].

The animal test technique is essentially used for the evaluation of the smoke toxicity. The tests involve the exposure of animals (minimum of six male rats) in an enclosure to the smoke released by the thermal decomposing composite materials [10,54].

The method involves a series of experiments performed at different concentrations of smoke to evaluate the incapacitation index value (EC50) or lethality index value (LC50) for a particular combustion condition. EC50 indicates the smoke condition under which 50\% of the animals are incapacitated, while LC50 reveals the smoke condition under which 50\% of the animals are killed [10,71].

Therefore, the lower the index values, the higher the toxicity of the combustion products from the composite materials $[74,75]$.

\subsection{Post-Fire Accidents and Safety Regulations}

The growth of the use of polymer composite materials has been a phenomenon since 1960, with diverse applications in spacecraft, aircraft, boats, ship, automobiles, civil infrastructure, sporting goods, and consumer products [76,77].

In addition, the use of composites will continue to grow in the coming years with emerging end-use such as large bridge structures, engine machinery, offshore platforms, computer hardware, and biomedicals devices. However, a critical challenge facing the growing use of polymer composites is their high combustibility.

Thus, strict fire safety regulations are enforced by the aviation authorities because of their potential fire risk. For example, the Federal Aviation Administration regulates the utilisation of materials inside aircraft cabins [78].

Flame-resistant phenolic laminate composites are often used in cabins, which accounts for about $80-90 \%$ of the interior furnishings of the modern-day passenger aircraft. The specific areas of application of these composites include the interior wall panels, partition ceiling panels, galley structures, large cabinet walls, overhead stowage bins, and structural flooring [79].

Furthermore, flame-retardant carbon-reinforced laminate composites are often used in load-bearing aircraft structures due to their improved mechanical performance when compared to the conventional aerospace grade-epoxies without the use of fire retardant. Despite the relatively few crashes of aircrafts caused by fire, it is interesting to state that fire is the fifth highest cause of deaths. Aircraft fires are very dangerous because there is little time span to fight and suppress or extinguish the fire before the crew and passengers are evacuated [24,78,80-82].

The heat from such fires is the cause of some deaths; however, most fatalities are as a result of high concentration of hydrogen cyanide $(\mathrm{HCN})$, carbon monoxide $(\mathrm{CO})$, and other toxic gases $[81,83,84]$.

In August 1985, a post-crash fire accident occurred when a Boeing 737 operated by the British midlands had an engine explosion at the Manchester Airport on take-off. The accident explosion ignited about $4000 \mathrm{~L}$ of fuel and claimed the lives of 55 people due to the inhalation of the smoke and toxic fumes released from the burning fuel and cabin materials. The aftermath of the accident called for measures to prevent cabin materials from releasing poisoning gases and thus lighting the significance of using excellent flameretardant materials $[62,66,85,86]$.

Similarly, in May 1996, one of the worst accidents due to fire occurred when a Valujet DC-9 crashed into the Florida everglades. Immediately after take-off, a fire developed in the forward cargo which led to the crash of the aircraft, killing all 105 passengers and crew $[69,76]$.

The aftermaths of the investigations revealed that the accident was caused by the loss of control of the flight control systems due to extreme heat release and structural collapse [87]. 
Hence, the FAA have proposed and sponsored the 'Fire-Safety Materials' program in order to design and develop fire-retardant polymer composite materials for applications in aircraft that can withstand survivable aircraft cabin conditions for at least 10 to $15 \mathrm{~min}$ in post-crash fuel fires so as to prevent deaths $[28,52,88,89]$.

Composite materials have also been widely used in sea-craft that range from small yachts and powerboats to large naval ships and passenger ferries. The specific areas of applications as sea-craft materials are the super structures: the hull, bulkheads, masts, and piping systems $[80,90]$.

Fire is sadly a frequent danger on boats. Fibre glass-reinforced composites are largely to fabricate most boats. However, when they are exposed to fire, they rapidly ignite, and the source of ignition is usually from fuel leakage or electrical problems [91-94].

In 1999, there was a report by the United State Coast Guard that stated that over 200 boat fires occurred with many leading to complete destruction of the composite hull. In addition, it was reported that fires led to 4 deaths, 250 injures (most of them are from burns or smoke inhalation), and nearly $\$ 4$ million in property damage $[95,96]$.

In November 2002, the first reported case of the loss of a composite naval ship due to fire occurred on a Norwegian minesweeper, which revealed the potential hazard of polymer composites. The source of the fire was from the propulsion system of KNM Orkla (a minesweeper built of sandwich composite material) $[12,97,98]$. Then, the ship was engulfed by fire and burnt for more than $24 \mathrm{~h}$ before capsizing, disintegrating, and sinking. However, it is believed that the sandwich composite hull aided the fire spread due to its high combustibility $[12,97,98]$. In addition, the composites produced a large amount of smoke and fumes, thereby forcing the passengers to exit the ship. This fire was severe with the radiant heat flux above $75 \mathrm{~kW} / \mathrm{m}^{2}$ and a flame temperature exceeding $1000{ }^{\circ} \mathrm{C}$ [99-102].

Thus, punitive fire standards are enforced on the use of polymer composites in ships such as the International Convention for the Safety of Life at Sea (SOLAS) regulations and the International Maritime Organization (IMO) established in 1948 by the United Nations agency with the mandate of enacting the policy guiding the fire performance for composite materials that will guarantee passengers' safety [60,72,103-106].

\section{Fire Safety Performance and Smoke (Toxic Gas) Emission of Composites}

This section entails the research works reported by various research teams on the use of different classes of scales of the thermal and fire reaction devices to investigate and evaluate the fire hazard risk and both the qualitative and quantitative assessment of the gas emission species during the combustion reaction of the polymer composite materials.

\subsection{Small Scale}

The small-scale devices are utilised in the characterisation of the intrinsic materials properties and to evaluate the reaction mechanism of the material e.g., TGA, MCC, PFC, etc. In addition, the FTIR and mass spectrometry techniques are employed for the gas emission examination. Table 2 highlighted some vital results of the thermal tests conducted by researchers using the small-scale facilities.

The blends of cotton/alginate fibres were prepared using alginate fibres. Alginate fibres improved the thermal stability of specimens at higher temperatures when compared to cotton fibres, as evidenced by an increase in residual chars. A Pyrolysis Combustion Fire Calorimeter (PCFC) was utilised to study the flame retardancy of the specimens [18].

Bin et al. discovered that the inclusion of alginate fibres significantly reduces the heat release of combustion (HRC) and thermal heat release (THR) values of cotton/alginate blended fibres with various cotton/alginate fibre weight ratios. This finding suggests that alginate fibres limit the emission of combustible gases in cotton/alginate blended fibres, lowering pHRR values.

In 2010, Craig et al. developed a methodology of assessing the comparative hazard from the thermal degradation products of polymer materials using the animal technique methodology. The acute lethality and histopathological examinations were studied, and 
the rankings of the polymeric materials evaluated are as follows: PTFE $>$ PVC $>$ PU $>$ GFRP > Copper-coated wire with mineral insulation [10].

Table 2. The experimental working scale adapted to investigate the thermal decomposition of composites.

\begin{tabular}{|c|c|c|c|c|c|c|c|c|}
\hline \multirow{2}{*}{$\begin{array}{l}\text { Specimens } \\
\text { (Codes) }\end{array}$} & \multicolumn{3}{|c|}{ MCC } & \multicolumn{4}{|c|}{ TGA } & \multirow{2}{*}{ Citations } \\
\hline & $\begin{array}{c}\text { pHRR } \\
\text { (W/g) }\end{array}$ & THR (kJ/g) & $\begin{array}{c}\text { TpHRR } \\
\left({ }^{\circ} \mathrm{C}\right)\end{array}$ & $\mathrm{T}_{-5}\left({ }^{\circ} \mathrm{C}\right)$ & $\mathrm{T}_{-50}\left({ }^{\circ} \mathrm{C}\right)$ & $\mathrm{T}_{\max }\left({ }^{\circ} \mathrm{C}\right)$ & $\begin{array}{c}\text { Solid } \\
\text { Residue } \\
(\%) \text { at } 700 \\
{ }^{\circ} \mathrm{C}\end{array}$ & \\
\hline RTS & 120.2 & 25.8 & 339.1 & - & - & - & - & \\
\hline APP-ST-RTS & 102.6 & 21.3 & 337.8 & - & - & - & - & \\
\hline APP-DSP-RST & 79.4 & 15.2 & 338.2 & - & - & - & - & [15] \\
\hline APP-HPDSP-RST & 89.8 & 18.5 & 336.9 & - & - & - & - & \\
\hline PLA & - & - & - & 324 & 332 & 355 & 0.37 & \\
\hline PLA/C15A & - & - & - & 318 & 332 & 361 & 1.16 & [18] \\
\hline PLA/C20A & - & - & - & 323 & 334 & 362 & 1.71 & \\
\hline PLA/C30B & - & - & - & 328 & 338 & 363 & 2.05 & \\
\hline TPOSS & - & - & - & 188 & 320 & 200 & 44.3 & \\
\hline TGIC & - & - & - & 196 & 240 & 237 & 1.1 & \\
\hline NPOSS & - & - & - & 169 & 330 & 193 & 21.0 & [19] \\
\hline EP & - & - & - & 308 & 399 & 352 & 0.2 & \\
\hline EP/NPOSS & - & - & - & 231 & 398 & 353 & 1.8 & \\
\hline ABS & 472 & 44 & - & - & - & - & - & \\
\hline ABS1 & 421 & 35 & - & - & - & - & - & [20] \\
\hline ABS2 & 414 & 36 & - & - & - & - & - & \\
\hline ABS3 & 350 & 35 & - & - & - & - & - & \\
\hline $\mathrm{Si} 0$ & 280 & 13.4 & 437 & 243 & 420 & - & 2.8 & \\
\hline Si1 & 65 & 4.7 & 323 & 304 & 423 & - & 17.3 & \\
\hline $\mathrm{Si} 2$ & 77 & 6.1 & 343 & 275 & 405 & - & 9.0 & [21] \\
\hline $\mathrm{Si} 3$ & 69 & 3.6 & 334 & 299 & 445 & - & 15.3 & \\
\hline Si4 & 89 & 3.9 & 338 & 298 & 451 & - & 12.4 & \\
\hline MFAPP & - & - & - & 336 & - & 359 & 56.7 & \\
\hline $\mathrm{EP}$ & - & - & - & 337 & 403 & 407 & 3.4 & [22] \\
\hline EP/MFAPP & - & - & - & 331 & 384 & 372 & 14.8 & \\
\hline Neat Resin & 418.5 & 23.6 & 390 & - & - & - & - & \\
\hline Resin + APP & 270.2 & 13.3 & 384 & - & - & - & - & [23] \\
\hline Resin + S-APP & 311.3 & 15.4 & 383 & - & - & - & - & \\
\hline Resin + MPP & 277.8 & 13.6 & 384 & - & - & - & - & \\
\hline $\mathrm{EP}$ & - & - & - & 337 & 403 & 407 & 7.4 & \\
\hline EM & - & - & - & 326 & 384 & 377 & 19.5 & [24] \\
\hline EMC7/1 & - & - & - & 314 & 376 & 372 & 20.4 & \\
\hline
\end{tabular}

MCC: micro-combustion calorimeter, TGA: thermogravimetric analysis, pHRR: the peak of heat release rate THR: total heat release, TpHRR: time to the peak of heat release rate, $\mathrm{T}_{-5}$ : time taken for $5 \%$ of the specimen to decompose, $\mathrm{T}_{-50}$ : time taken for $50 \%$ of the specimen to decompose, $\mathrm{T}_{\max }$ : time taken for the specimen to reach the peak of decomposition.

In 2018, Chuanmei et al. [37] studied the flame-retardant and thermal decomposition properties of thermoplastic polyurethane (TPU) polymer composites based on HGM@[EOOEMIm] $\left[\mathrm{BF}_{4}\right]$, which is prepared by the modification of hollow glass microsphere (HDM) with ionic liquid [EOOEMIm] $\left[\mathrm{BF}_{4}\right]$.

The smoke-density test results revealed that the ionic liquid can remarkably decrease the amount of smoke production. The TGA results also revealed that the ionic liquid can improve the thermal stability of the TPU composites by promoting char formation in the combustion process. The flame retardancy and thermal stability of UV-curable epoxy acrylate (EA) nanocomposites based on organophilic $\alpha-\mathrm{ZnP}(\mathrm{OZnP})$ have been studied by Weiyi et al. [107]. 
Ding et al. [108] evaluated the effect of 'green' carbon sources-for example starch, distarch phosphate (DSP), with acid source ammonium polyphosphate (APP)—on the flame retardancy of reconstituted tobacco sheets (RST).

The TGA results showed that the starch-based fire-retardant coating promoted the char formation and inhibited char combustion due to the mechanism of the cross-linked phosphate ester groups in the carbon sources. While the FTIR and MS analysis of the gaseous products shows that the modified RTSs release comparative harmful compounds such as $\mathrm{CO}$ and carbonyl compounds [22].

The results of the MCC tests revealed a notable reduction in the heat release rate (HRR) and the peak of heat release rate (pHRR) relative to pure EA and the flame-retardant film without OZnP. In the course of thermal degradation, EA1 was easily degraded and released more gaseous compounds compared with EA2. The presence of OZnP could retard the motion and breakdown of the parent chain of the matrix resin during the thermal decomposition process.

In 2015, Lei et al. investigated the thermal degradation of hydroquinone bis (di-2methylphenylphosphate) (HMP) by thermogravimetry (TG) coupled with Fourier Transform Infrared Spectroscopy (FTIR). The HMP disintegrated in two steps under air, according to semi-quantitative TG-FTIR studies. The HMP degraded into benzyl alcohol, hydroquinone phosphate step, carbon dioxide, water, and alkyne in the first step from 385 to $452{ }^{\circ} \mathrm{C}$, and carbon dioxide, water, and alkyne in the second step from 491 to $800{ }^{\circ} \mathrm{C}$ [47].

While examining the effects of interspace distance and the potential chemical reaction between PLA and the montmorillonite modifier (cloisite 15A, 20A, and 30B), Esra et al. (2016) discovered that the method of polymer incorporation into the nanocomposite is highly dependent on the mixing technique, the interspacing between the clay layers, and, most importantly, the type of organic modifier used [46]. In addition, Esra et al. showed evidently from the result of the TGA that as the amount of cloisite increased, a slight increase in the char yield mainly due to the clay particles incorporated was detected.

The relative yield of products due to trans-esterification processes was reduced in the presence of water vapour. As the partial pressure of water was increased, the thermal degradation of PLA nanocomposites was changed to a low temperature.

Kun et al. [65] used a reaction between trisilanolisobutyl-POSS and triglycidyl isocyanurate to make a functional polyhedral oligomeric silsequioxane (NPOSS) with an epoxy ring linked, and then, they made a halogen-free epoxy composite containing silicon/nitrogen. According to the findings of the MCC, the presence of NPOSS (10\% weight ratio) in epoxy resin (EP) can reduce its peak heat release rate by roughly $30 \%$. DSC, TG, and TG-FTIR were used to characterise the thermal oxidation and degradation behaviour of EP and EP/NPOSS composites. In the condensed phase, NPOSS can slow down the movement and scission of EP polymeric chains, forming a solid charred layer that protects the underlying materials from further combustion.

Maria et al. [81] examined the thermal degradation and fire behaviour of an unsaturated polyester resin with phosphate-based fire-retardant additives and its corresponding glass fibre composites in 2012. Three phosphate-based fire retardants were added to the commercial polyester resin at a ratio of 35\% w/w: ammonium polyphosphate, silane-coated ammonium polyphosphate, and melamine pyrophosphate.

Then, the effects of the fire retardants on polymer thermal decomposition and smallscale fire behaviour were investigated utilising dynamic thermogravimetric tests (DTG) at various heating rates and microcalorimetric measurements using a FAA micro-calorimeter in accordance with ASTM D07309-07. According to the findings of Maria et al., the ammonium polyphosphate-containing resin outperformed the other systems in terms of thermal and fire performance. A vacuum infusion process was utilised to make unidirectional glass fibre composites.

Karen et al. (1997) examined the decomposition products of fire-retarded glass fibrereinforced epoxy composites using FTIR spectroscopy. 
This bench-scale study focused on the identification and quantification of toxic species. The FTIR spectroscopy identified toxic effluent species over a wide range of composite exposure temperatures $\left(100\right.$ to $\left.1000{ }^{\circ} \mathrm{C}\right)$, during pyrolysis and combustion [64].

Formaldehyde, methanol, carbon mono oxide, nitric oxide, methane, and benzene were identified by the spectral analysis. In addition, as the thermal decomposition progressed, their oxides concentrations were observed. Thus, the material fire behaviour profile created by the decomposition mechanisms combined by the physical observations provides an evaluation of product fire safety performance and a basis for early fire detection.

$\mathrm{Ku}$ et al. [92] examined the thermal degradation and flame retardancy of epoxy (EP) composites containing micro-crystalline cellulose whiskers (MCW) and micro-encapsulated ammonium polyphosphate (MFAPP).

When compared to EP and EP/MFAPP, the MCC test at $6 \mathrm{wt} \%$ loading revealed that its heat release rate lowers. The explanation for this is that EP composites with MCW have a higher charring capability in a fire.

$\mathrm{Ku}$ et al. also revealed from the TG and TG-FTIR results that at lower temperature, MFAPP stimulates the dehydration of MCW and EP and releases gases that are useful for the formation of an intumescent char.

Furthermore, at high temperatures, the residue does not emit any dangerous gas and acts as an effective insulation layer on the sample's surface, protecting the underlying material from fire.

\subsection{Medium Scale}

Researchers have performed quite a number of studies on the fire behaviour and the protection of polymer composite materials used especially as vital components in the transport sectors and building element under fire condition [109]. The bench-scale platform of the medium scale has provided significant fire testing parameters that indicate the fire reaction and fire resistance of the materials assessed (as shown in Tables 3-6) e.g., a cone calorimeter test (CCT), limiting oxygen index (LOI), and underwriter's laboratories (UL-94). Thus, the results have been a useful guide in the evaluation of the fire hazard risk and the smoke and toxic gases examination. 
Table 3. The experimental working scales adopted to investigate the flammability and combustibility of composites [25].

\begin{tabular}{|c|c|c|c|c|c|c|c|c|c|c|c|c|c|}
\hline $\begin{array}{l}\text { Specimens } \\
\text { (Codes) }\end{array}$ & $\begin{array}{c}\text { pHRR } \\
\left(\mathrm{kW} / \mathrm{m}^{2}\right)\end{array}$ & $\begin{array}{c}\text { THR } \\
\left(\mathrm{MJ} / \mathrm{m}^{2}\right)\end{array}$ & TTI (s) & $\begin{array}{l}\mathrm{pHHR} / \mathrm{t}_{\mathrm{ig}} \\
\left(\mathrm{kWm}^{2} \mathrm{~s}^{1}\right)\end{array}$ & $\begin{array}{l}\text { Residual } \\
\text { Mass (\%) }\end{array}$ & $\begin{array}{c}\text { TSP } \\
\left(\mathrm{m}^{2} / \mathrm{kg}\right)\end{array}$ & $\begin{array}{c}\text { TSR } \\
\left(\mathrm{m}^{2} / \mathrm{m}^{2}\right)\end{array}$ & $\begin{array}{c}\text { SEA } \\
\left(\mathrm{m}^{2} / \mathrm{kg}\right)\end{array}$ & $\begin{array}{l}\text { CO Yield } \\
\text { (g/kg) }\end{array}$ & $\begin{array}{c}\mathrm{CO}_{2} \text { Yield } \\
(\mathrm{kg} / \mathrm{kg})\end{array}$ & LOI & UL-94 & Citations \\
\hline A-10 & 361 & 67 & 31 & 16.2 & - & 20.9 & - & 762 & 0.128 & - & 25.4 & $\mathrm{HB}$ & \multirow{7}{*}{ [26] } \\
\hline B-10 & 429 & 60 & 54 & 8.1 & - & 20.4 & - & 838 & 0.199 & - & 25.0 & $\mathrm{HB}$ & \\
\hline AS-5 & 348 & 63 & 58 & 6.0 & - & 21.8 & - & 918 & 0.333 & - & 26.4 & $\mathrm{HB}$ & \\
\hline BS-5 & 335 & 59 & 60 & 5.6 & - & 19.1 & - & 756 & 0.053 & - & 27.7 & $\mathrm{HB}$ & \\
\hline BS-0 & 433 & 66 & 60 & 8.2 & - & 17.7 & - & 505 & 0.074 & - & 28.0 & $\mathrm{HB}$ & \\
\hline B1S-5 & 306 & 55 & 60 & 5.1 & - & 18.9 & - & 728 & 0.268 & - & 28.8 & $\mathrm{HB}$ & \\
\hline B1S-10 & 416 & 63 & 59 & 5.8 & - & 16.7 & - & 614 & 0.279 & - & 29.0 & HB & \\
\hline Pure PLA & 752 & 171.1 & 37 & 209 & -3.66 & 40.8 & - & - & 0.037 & - & 21.5 & NR & \multirow{8}{*}{ [27] } \\
\hline MX0.5 & 920 & 170.4 & 32 & 209 & -0.30 & 47.5 & - & - & 0.030 & - & 20.0 & NR & \\
\hline MX1.0 & 803 & 167.7 & 32 & 207 & 0.00 & 41.0 & - & - & 0.028 & - & 20.0 & NR & \\
\hline MX2.0 & 715 & 178.9 & 35 & 254 & 0.53 & 20.8 & - & - & 0.035 & - & 20.5 & NR & \\
\hline F12.0 & 431 & 136.3 & 41 & 246 & 4.04 & 457.4 & - & - & 0.097 & - & 30.0 & V-1 & \\
\hline F11.5MX0.5 & 263 & 144.5 & 39 & 389 & 5.86 & 178.1 & - & - & 0.062 & - & 33.0 & V-0 & \\
\hline F11.0MX1.0 & 266 & 142.7 & 35 & 415 & 7.82 & 244.3 & - & - & 0.059 & - & 34.5 & V-1 & \\
\hline $\mathrm{F} 10.0 \mathrm{MX} 2.0$ & 410 & 149.6 & 30 & 252 & 6.36 & 282.0 & - & - & 0.072 & & 28.0 & $\mathrm{~V}-1$ & \\
\hline \multirow{2}{*}{$\begin{array}{c}\text { Pure WPC } \\
\text { WPC }+3 w t \% \text { FR } \\
\text { WPC }+10 w t \% \\
\text { FR }\end{array}$} & 347 & 191 & 26 & - & 16.4 & - & - & - & - & - & - & - & \multirow{2}{*}[28]{} \\
\hline & 311 & 175 & 22 & - & 25.2 & - & - & - & - & - & - & - & \\
\hline
\end{tabular}


Table 4. Cone calorimeter (irradiance, $50 \mathrm{~kW} / \mathrm{m}^{2}$ ), LOI, and UL-94 results.

\begin{tabular}{|c|c|c|c|c|c|c|c|c|c|c|c|c|c|}
\hline $\begin{array}{l}\text { Specimens } \\
\text { (Codes) }\end{array}$ & $\begin{array}{c}\text { pHRR } \\
\left(\mathrm{kW} / \mathrm{m}^{2}\right)\end{array}$ & $\begin{array}{c}\text { THR } \\
\left(\mathrm{MJ} / \mathrm{m}^{2}\right)\end{array}$ & TTI (s) & $\underset{\text { (s) }}{\mathrm{pHRR} / \mathrm{t}_{\mathrm{ig}}}$ & $\begin{array}{l}\text { Residual } \\
\text { Mass (\%) }\end{array}$ & $\begin{array}{c}\text { TSP } \\
\left(\mathrm{m}^{2} / \mathrm{kg}\right)\end{array}$ & $\begin{array}{c}\text { TSR } \\
\left(\mathrm{m}^{2} / \mathrm{m}^{2}\right)\end{array}$ & $\begin{array}{c}\text { SEA } \\
\left(\mathrm{m}^{2} / \mathrm{kg}\right)\end{array}$ & $\begin{array}{l}\text { CO Yield } \\
\text { (g/kg) }\end{array}$ & $\begin{array}{c}\mathrm{CO}_{2} \text { Yield } \\
(\mathrm{kg} / \mathrm{kg})\end{array}$ & LOI & UL-94 & Citations \\
\hline AcF20 (2 mm) & 285.7 & 19.6 & 30 & - & 35.5 & - & - & - & 0.04 & 1.68 & - & - & \multirow{6}{*}{ [1] } \\
\hline AcF40 (4 mm) & 280.4 & 39.9 & 49 & - & 28.2 & - & - & - & 0.10 & 1.50 & - & - & \\
\hline AcF5 (5 plies) & 162.0 & 13.2 & 17 & - & 35.0 & - & - & - & 0.36 & 1.49 & - & - & \\
\hline AcF7 (7 plies) & 144.0 & 15.5 & 24 & - & 39.0 & - & - & - & 0.65 & 1.16 & - & - & \\
\hline AcF8 (8 plies) & 169.4 & 11.1 & 27 & - & 28.9 & - & - & - & 0.21 & 1.19 & - & - & \\
\hline AcF9 (9 plies) & 175.3 & 15.9 & 31 & - & 17.2 & - & - & - & 0.47 & 1.63 & - & - & \\
\hline Cotton & 100 & 10.0 & 22 & 73 & 0.0 & 2.2 & - & - & & - & - & - & \multirow{5}{*}{ [18] } \\
\hline Cotton4/alginat1 & 89 & 9.40 & 28 & 86 & 2.7 & 0.2 & - & - & & - & - & - & \\
\hline Cotton5/alginat5 & 68 & 7.20 & 42 & 87 & 8.4 & 0.2 & - & - & & - & - & - & \\
\hline Cotton1/alginat4 & 46 & 9.70 & 71 & 97 & 10.4 & 1.9 & - & - & & - & - & - & \\
\hline Alginate & 49 & 3.50 & 103 & 123 & 23.9 & 0.9 & - & - & & - & - & - & \\
\hline PP & 1620 & 110 & 24 & - & - & - & 980 & - & 36.6 & 3.16 & - & - & \multirow{5}{*}{ [3] } \\
\hline PP/MWNT & 931 & 102 & 17 & - & - & - & 1310 & - & 44.2 & 2.89 & - & - & \\
\hline PB & 1420 & 111 & 35 & - & - & - & 1090 & - & 36.4 & 3.01 & - & - & \\
\hline PB/MWNT & 830 & 108 & 18 & - & - & - & 1545 & - & 40.5 & 2.90 & - & - & \\
\hline PE/MWNT & 920 & 111 & 37 & - & - & - & 1315 & - & 35.1 & 3.14 & - & - & \\
\hline
\end{tabular}

TSP: total smoke production, TSR: total smoke release, SEA: specific extinction area. 
Table 5. Cone calorimeter (irradiance, $35 \mathrm{~kW} / \mathrm{m}^{2}$ ), LOI, and UL-94 results.

\begin{tabular}{|c|c|c|c|c|c|c|c|c|c|c|c|c|c|}
\hline $\begin{array}{l}\text { Specimens } \\
\text { (Codes) }\end{array}$ & $\begin{array}{c}\text { pHRR } \\
\left(\mathrm{kW} / \mathrm{m}^{2}\right)\end{array}$ & $\begin{array}{c}\text { THR } \\
\left(\mathrm{MJ} / \mathrm{m}^{2}\right)\end{array}$ & TTI (s) & $\underset{\text { (s) }}{\mathrm{pHRR} / \mathrm{t}_{\mathrm{ig}}}$ & $\begin{array}{l}\text { Residual } \\
\text { Mass (\%) }\end{array}$ & $\begin{array}{c}\text { TSP } \\
\left(\mathrm{m}^{2} / \mathrm{k}\right)\end{array}$ & $\begin{array}{c}\text { TSR } \\
\left(\mathrm{m}^{2} / \mathrm{m}^{2}\right)\end{array}$ & $\begin{array}{c}\text { SEA } \\
\left(\mathrm{m}^{2} / \mathrm{k}\right)\end{array}$ & $\begin{array}{l}\text { CO Yield } \\
(\mathrm{kg} / \mathrm{kg})\end{array}$ & $\begin{array}{c}\mathrm{CO}_{2} \text { Yield } \\
(\mathrm{kg} / \mathrm{kg})\end{array}$ & LOI & UL94 & Citations \\
\hline GRPBT & 417 & 53.6 & 49 & - & 35.5 & 354 & - & 520 & 0.052 & 1.64 & - & - & \multirow{3}{*}{ [4] } \\
\hline GRPBT/AHP & 121 & 40.5 & 30 & - & 28.2 & 222 & - & 388 & 0.144 & 1.15 & - & - & \\
\hline GRPBT/CHP & 101 & 42.8 & 38 & - & 35.0 & 198 & - & 249 & 0.122 & 1.42 & - & - & \\
\hline PPO & 467 & 110 & 97 & - & 26 & - & 1303 & - & 0.14 & - & 29 & V-0 & \multirow{6}{*}{ [60] } \\
\hline PPO-30AlPi & 130 & 102 & 125 & - & 52 & - & 1994 & - & 0.18 & - & 43 & $\mathrm{~V}-0$ & \\
\hline TPU & 613 & 111 & 84 & - & 6 & - & 1229 & - & 0.04 & - & 24 & $\mathrm{HB}$ & \\
\hline TPU-30AlPi & 447 & 108 & 70 & - & 13 & - & 3029 & - & 0.16 & - & 24 & V-0 & \\
\hline PP & 480 & 125 & 66 & - & 2 & - & 1305 & - & 0.04 & - & 17 & $\mathrm{HB}$ & \\
\hline PP-30AlPi & 524 & 111 & 73 & - & 10 & - & 2310 & - & 0.16 & - & 27 & $\mathrm{HB}$ & \\
\hline EP & 1063 & 76.1 & 59 & 130 & 11.9 & 71.4 & - & - & - & - & 26.2 & NR & \multirow{3}{*}{ [110] } \\
\hline $\mathrm{EP} / 10 \mathrm{APP}$ & 754 & 42.8 & 63 & 105 & 45.7 & 30.6 & - & - & - & - & 30.2 & NR & \\
\hline $\mathrm{EP} / 7.5 \mathrm{APP} / 2.5 \mathrm{BPOPA}$ & 576 & 42.6 & 61 & 100 & 47.2 & 25.9 & - & - & - & - & 33.1 & $\mathrm{~V}-0$ & \\
\hline $\mathrm{EP}$ & 1063 & 114 & 76 & - & 3 & - & 3626 & 829 & - & - & & $\mathrm{HB}$ & \multirow{4}{*}{ [111] } \\
\hline 20HS & 729 & 106 & 63 & - & 3 & - & 2768 & 636 & - & - & & $\mathrm{HB}$ & \\
\hline 20LHP & 166 & 37 & 59 & - & 50 & - & 1016 & 459 & - & - & & HB & \\
\hline 5HS/15LHP & 169 & 35 & 59 & - & 54 & - & 899 & 435 & - & - & & HB & \\
\hline
\end{tabular}

TSP: total smoke production, TSR: total smoke release SEA: specific extinction area. 
Table 6. CCT (irradiance, 50kW/ $\mathrm{m}^{2}$ ), LOI, and UL-94 results.

\begin{tabular}{|c|c|c|c|c|c|c|c|c|c|c|c|c|c|}
\hline Samples & $\begin{array}{c}\text { pHRR } \\
\left(\mathbf{k W} / \mathrm{m}^{2}\right)\end{array}$ & $\begin{array}{c}\text { THR } \\
\left(\mathrm{MJ} / \mathrm{m}^{2}\right)\end{array}$ & TTI (s) & $\begin{array}{c}\mathrm{pHRR} / \mathrm{t}_{\mathrm{ig}} \\
\text { (s) }\end{array}$ & $\begin{array}{l}\text { Residual } \\
\text { Mass (\%) }\end{array}$ & $\begin{array}{c}\text { TSP } \\
\left(\mathrm{m}^{2} / \mathrm{kg}\right)\end{array}$ & $\begin{array}{c}\text { TSR } \\
\left(\mathrm{m}^{2} / \mathrm{m}^{2}\right)\end{array}$ & $\begin{array}{c}\text { SEA } \\
\left(\mathrm{m}^{2} / \mathrm{kg}\right)\end{array}$ & $\begin{array}{c}\text { CO Yield } \\
(\mathrm{g} / \mathrm{kg})\end{array}$ & $\begin{array}{c}\mathrm{CO}_{2} \text { Yield } \\
(\mathrm{kg} / \mathrm{g})\end{array}$ & LOI & UL-94 & Citations \\
\hline $\mathrm{GF}_{30}-\mathrm{PBT}$ & 345 & 118 & 30 & 105 & 35.5 & - & 3987 & - & - & - & 20.0 & NR & \multirow{4}{*}{ [59] } \\
\hline $\mathrm{GF}_{30}-\mathrm{PBT} 10$ & 136 & 82 & 49 & 65 & 28.2 & - & 3958 & - & - & - & 23.2 & NR & \\
\hline $\mathrm{GF}_{30}-\mathrm{PBT} 20$ & 107 & 75 & 17 & 60 & 35.0 & - & 2747 & - & - & - & 28.5 & V-0 & \\
\hline $\mathrm{GF}_{30}-\mathrm{PBT} 25$ & 105 & 71 & 24 & 60 & 39.0 & - & 2101 & - & - & - & 32.5 & $\mathrm{~V}-0$ & \\
\hline Neat Furan & 682 & 30.9 & 98 & - & 44.0 & - & 117 & - & 0.0203 & 1.37 & - & - & \multirow{5}{*}{ [108] } \\
\hline F/AS-40 amino & 554 & 24.4 & 103 & - & 50.5 & - & 109 & - & 0.0249 & 1.42 & - & - & \\
\hline F/AS-40 isocy & 556 & 30.7 & 104 & - & 50.9 & - & 108 & - & 0.0277 & 1.41 & - & - & \\
\hline $\begin{array}{c}\mathrm{F} / \mathrm{PT}-40 \mathrm{AS} \\
\text { isocy }\end{array}$ & 507 & 23.8 & 100 & - & 49.7 & - & 96 & - & 0.0241 & 1.30 & - & - & \\
\hline $\begin{array}{l}\text { F/PT-40AS } \\
\text { amino }\end{array}$ & 569 & 26.9 & 95 & - & 50.2 & - & 92 & - & 0.0239 & 1.31 & - & - & \\
\hline
\end{tabular}

TSP: total smoke production, TSR: total smoke release SEA: specific extinction area. 
Gallo et al. (2013) prepared a flame-retarded styrene butadiene rubber composite. A well-dispersed spherically-shaped amorphous silicon dioxide with a broad size distribution (Sidistar) was used as the flame retardant in combination with two different kinds of aluminium trihydride (ATH): a finely precipitated form (ATH-A) and a coarse-grained form (ATH-B). Gallo et al. then investigated the thermal stability, gas transport, and fire properties with and without the Sidistar [21].

The addition of Sidistar (synergist) slowed the release of pyrolysis gases through the matrix, lengthening the time before ignition. The oxygen index of materials with Sidistar and those with enhanced ATH content increased slightly in the LOI test. When the ATH content was raised and Sidistar was added, the horizontal burning rate in UL 94 indicated flame retardancy. When Sidistar was added to the cone calorimeter experiments, fire hazards such as pHRR, TpHRR, and THR were reduced, as were fire risks when ATH-B was used instead of ATH-A and the ATH content was raised.

The flame-retardant Disflamoll TP LXS 51064 based on an ammonium polyphosphate (APP) ester was incorporated in wood biocomposite without the use of a carbonising agent due to the change in the chemical nature of the material. The heteroatoms of the cellulose and the aromatic rings of lignin act as carbonisation agents for residue formation. Its exact disintegration mechanism, as well as its fire-retardant mechanism, have yet to be explored.

Therefore, in 2020, Henrik and Ulrike studied the flame retardant relative to its thermal decomposition and its mode of action in wood-plastic composites (WPCs) by using cone calorimeter (fire tests) and FTIR (pyrolysis and gas emission investigation) [13].

Basically, the addition of the non-flammable fire-retardant (FR) to the WPC material reduced the HRR. In fact, a numerical value of $347 \mathrm{~kW} / \mathrm{m}^{2}$ was obtained with $3 \mathrm{wt} \% \mathrm{FR}$, and then, it was further reduced to $311 \mathrm{~kW} / \mathrm{m}^{2}$ when $10 \mathrm{wt} \%$ FR was incorporated.

The mechanism of the flame retardant was found to act majorly in the condensed phase by increasing the quantity of residue formed by the wood component of the WPC. Further flame dilution is achieved by the production of water, ammonia, and carbon dioxide during the decomposition of the flame retardant [108].

Using a cone calorimeter, Talal et al. [1] investigated the effect of various layers (thickness) on the thermal degradation and fire reaction properties of carbon fibre-reinforced epoxy and fibre-reinforced phenolic resin samples. The key fire reaction parameters, such as time-to-ignition and the peak of heat release rates, were shown to be dependent on the number of layers, according to the researchers' findings. In addition, the amount of smoke and the carbon dioxide emission levels during the thermal degradation were found to decrease as the number of layers increased [7]. It can be noticed for epoxy-reinforced composite that the total smoke production (TSP) of the smoke released in case of the specimen $4.2 \mathrm{~mm}$ is much higher than in case of the specimen $2.1 \mathrm{~mm}$. However, the smoke is released much quicker in case of the thinner composite (80 s), while the thicker composite has a peak around $120 \mathrm{~s}$. Similarly, as anticipated, the quantity of smoke generated for phenolic composite was found to increase with an increase in the number of layers, except for the one with nine plies.

Blended fibres of cotton/alginate can be utilised as filling materials for the production of toys, pillows, and sleeping bags. According to the results obtained by Bin et al., the flammability of the fibre blend can meet the combustion requirements for its outdoor applications. Recently, Bin et al. (2020) prepared cotton/alginate blends fibres [18]. Relative to cotton fibres, alginate fibres enhanced the thermal stabilities of the specimens at higher temperatures, showing in the increase in the char residues.

It also enhanced the flame-retardant properties and fire behaviour. Relative to that of cotton fibres, there are 26\% (cotton 4 /alginate 1 ), 43\% (cotton5/alginate 5 ), and 68\% (cotton1/alginate4) reductions in FIGRA, respectively. As revealed in Table 4, the lower FIGRA values of cotton/alginate blended fibres mean the lower fibre hazard of the materials [109].

The alginate fibres clearly reduced the total heat release, peak heat release rate, total smoke production, and the $\mathrm{CO}_{2}$ production. 
In 2008, Albert et al. enhanced the flame retardancy of polypropylene (PP) via the chemical activity (catalytic effects) of carbon nanotubes and polyhedral oligomeric silsesquioxane (POSS) in the course of thermal degradation and combustion.

The inclusion of nanotubes was discovered to accelerate the oxidative dehydrogenation in PP, resulting in the formation of a stable carbon char surface layer that acts as an efficient oxygen barrier. A similar action was performed by metal-containing polysilsequioxanes dispersed in PP [3,47].

Glass fibre-reinforced polymer composites' substantial fire dangers have severely hampered their research and applications. Wei et al. $[4,39]$ treated the composites with flame retardants to minimise their flammability. The usage of three trivalent metal hypophosphite halogen-free flame retardants $(\mathrm{Al}, \mathrm{La}, \mathrm{Ce})$ is investigated in this study. The thermal and combustion behaviour of glass fibre-reinforced polybutylene terephthalate (GRPBT) composites were quantitatively investigated using cone calorimeter and FTIR techniques. The results showed that the pHRR and TSP of GRPBT/cerium hypophosphite (CHp) composites were reduced by $76 \%$ and $44 \%$, respectively.

Table 5 reveals the work of Hongxia et al. [58,60], who examined the effects and mechanisms of aluminium phosphinate (AlPi) on the flame retardancy of three polymers: thermoplastic polyurethane (TPU), poly (2,6-dimethyl-1,4-phenylene oxide) (PPO), and polypropylene (PP).

Their fire reaction properties were assessed using the cone calorimeter test (CCT), vertical burning tests (UL-94), and limiting oxygen index (LOI).

The results revealed that the amount of AlPi needed to reach a V-0 UL-94 rating in the TPU, PPO, and PP matrices were $0 \mathrm{wt} \%, 30 \mathrm{wt} \%$, and $50 \mathrm{wt} \%$, respectively. Moreover, the addition of AlPi significantly increased the LOI values of PPO and PP. AlPi also decreased the pHHR of PPO and TPU, whereas that of PP increased. The flame inhibition process for AlPi/TPU and AlPi/PP could be attributed to the synergistic reaction of phosphorus and nitrogen in the gas phase during the burning process, therefore increasing the $\mathrm{CO}$ production.

As a result of its strong chemical resistance and mechanical qualities, epoxy resin (EP) is a widely utilised thermosetting resin in different industrial domains such as paints and electronic goods. EP, on the other hand, is extremely combustible, limiting its use. Therefore, Zong-Min et al. [58,110] synthesised a novel flame retardant of $\mathrm{P} / \mathrm{N}$-containing oligomer poly (piperazine phenyl-phosphamide) (BPOPA), which was used to improve the flame retardancy of EP resin/ammonium polyphosphate (APP).

The LOI value of EP containing 10\% APP alone was 30.2\%; however, the UL-94 received no rating.

$\mathrm{EP} / 7.5 \mathrm{APP} / 2.5 \mathrm{BPOPA}$ received a UL-94 V-0 grade with an LOI value of $33.1 \%$ when both $7.5 \mathrm{wt} \%$ APP and $2.5 \mathrm{wt} \%$ BPOPA were added to it.

Furthermore, when compared to EP/10APP, EP/7.5APP/2.5BPOPA had significantly reduced $\mathrm{pHRR}$ and TSP values.

Salasniska et al. [111] presented a novel intumescent fire retardant (FR) system based on ground hazelnut shell (HS) and L-histidinium dihydrogen phosphate-phosphonic acid (LHP) into epoxy resin (EP) in order to test their performance as fire retardants and their synergistic impact in 2020. Cone calorimeter and UL-94 tests were used to assess the burning behaviour and smoke production. FTIR was also used to analyse the volatile compounds that formed during the thermal decomposition and burning processes. Salasniska et al. found that the system containing $5 \mathrm{wt} \%$ of LHP led to the formation of a swollen char with numerous closed cells, which reduced the burning process as well as smoke emission.

Recently, Haowei et al. $(2020)[50,88]$ produced PLA/IFM composites with $\mathrm{Ti}_{3} \mathrm{C}_{2} \mathrm{MX}$ ene nanosheets by melt blending and then investigated the synergistic effects of MXene on the fire performance of the PLA/IFR system by substituting parts of the IFM with MXene.

It was revealed by Haowei et al. that the addition of $1 \mathrm{wt} \%$ MXene and $11 \mathrm{wt} \%$ IFR leads to an apparent increase in LOI (160.4\%) and an obvious reduction in pHRR (64.6\%), 
achieving a V-0 rating in UL-94. Furthermore, the cone calorimeter test results and other analysis of the carbon residues of PLA/IFR/MXene composites revealed that the nano $\mathrm{TiO}_{2}$ catalyst and two-dimensional nanosheet barrier efficiently enhanced the tendency of intumescent char formation by the PLA/IFR systems, thereby inhibiting further flame propagation and the spread of fire hazard.

Rigid poly(urethane-isocyanurate) (PIR) foams have been used in everyday life, and insulation materials play a vital role in the modern built environment, transportation, and industrial applications. However, the fire reactivity (thermal and chemical) of this kind of product remains one of the most limiting factors for their wider applications in some sectors.

Therefore, in order to increase the thermal stability of these types of foam, Damien et al. $[15,98]$ investigated at medium scale the effects of a reduced oxygen atmosphere on the reaction of fire of flame-retardant PIR foams. This experiment was carried out using a standard controlled-atmosphere cone calorimeter (ISO 5660) coupled with a Fourier Transform Infrared Spectrometer. Damien et al. presented and discussed the dependence of the results on both oxygen concentration (from 0 up to ambient condition) and irradiance level $\left(20\right.$ to $\left.50 \mathrm{~kW} / \mathrm{m}^{2}\right)$. At the end, the chemical compositions of the identified gaseous products were qualified and quantified during the decomposition and combustion processes. The combustion reaction in the gaseous phase releases mainly $\mathrm{CO}_{2}$, $\mathrm{CO}$, and $\mathrm{H}_{2} \mathrm{O}$ as well as other species such as HCN and HCL.

In 2015, Zhuoli et al. [72,97] investigated the thermo-oxidative degradation behaviour and fire performance of both homogenous and heterogenous high-impact polystyrene (HIPS). The high-impact polystyrene (HIPS)-based composite was alternatively filled by magnesium hydroxide (MH) and microencapsulated red phosphorus (MRP) flame retardants and pure HIPS sheets; thus, a HIP/MH/MRP composite with an alternating layered structure was successfully prepared through layer-on-layer melt laminating.

In comparison to its homogeneous counterpart containing the same quantity of flame retardant, the alternating composite demonstrates higher thermo-oxidative stability, flame retardancy, smoke suppression, and decreased toxic gas emission. The alternating composite can produce not only more charred residue but also more continuous and compact residue, which acts as an insulator on the composite surface and prevents heat transmission and mass transfer between the flame in the gas phase and the underlying polymers in the condensed phase.

Furthermore, the remarkable decreased smoke and toxic gas release revealed by the alternating composite in the cause of the combustion process is extremely important to reduce the harm to people in case of fires.

Zhuoli et al. summarised on the whole that the fire safety performance of the alternating composite improves to a large extent. This research work (as shown in Table 6) focus presents another technique to further increase the flame retardancy and smoke inhibition of polymer composites. The thermal decomposition and fire behaviour of an unsaturated polyester resin and the corresponding glass fibre (GF) composites were investigated.

In order to improve the fire behaviour of the polyester resin, different phosphate fire retardants, ammonium polyphosphate (APP), silane-coated ammonium polyphosphate (S-APP), and melamine pyrophosphate (MPP) were dispersed within the resin.

According to Maria et al. [81,112], using the cone calorimeter, a reduction of $\mathrm{pHRR}$ $(21 \%)$ and THR (39\%) for the fire-retarded composite were measured.

Thus, the findings of the researchers indicated that APP is efficient as a flame retardant of polyester-based glass fibre-reinforced composites due to the capacity to form a goodquality char.

Compared with poly (butylene terephthalate) (PBT), glass fibre-reinforced (butylene terephthalate) (GF-PBT) is difficult to flame retard with halogen-free flame retardants. In the investigation by Li et al. [58], aluminium salt of hypophosphorous acid (AP) was used as a flame retardant for GF-PBT. The addition of AP to the composites could result in an increase in LOI value, a UL-94 V-0 $(1.6 \mathrm{~mm})$ classification, and a better fire performance in 
CCT. Furthermore, the mechanical properties of the flame-retardant composites were not deteriorated, retaining an acceptable level.

Furan resin nanocomposites packed with silica nanoparticles were synthesised by Marco et al. [42,108]. A commercially available water-based suspension of silica particles was used to develop a dispersion method that could be easily scaled up to the industrial level. To improve the interaction between the silica particles and the matrix, various treatments with silanes were carried out. Although furan resin has a minimal fire danger by itself, the introduction of silica nanoparticles improves its performance in both flaming combustion and thermal resistance of the combustion char. This is owing to the protective silica skin that forms on the deteriorating furan resin as it burns.

\subsection{Large Scale}

The Federal Aviation Administration (FAA) developed the NexGen burner to replace the traditional oil burners used for mandatory fire certification tests on power plantrelated components. Since it has the capacity to adjust both air and fuel flow rates, this is conceivable. The time to failure and mass loss of several composites during combustion are shown in Table 7.

Table 7. Fire degradation of composites during combustion process.

\begin{tabular}{|c|c|c|c|c|c|}
\hline Specimens (Codes) & Time to Failure (s) & ML (\%) & $\operatorname{HRR}\left(\mathrm{kW} / \mathrm{m}^{2}\right)$ & Flame Temp. $\left({ }^{\circ} \mathrm{C}\right)$ & Citations \\
\hline GFC (PVC) & 45.0 & - & $116 \pm 10$ & $1100 \pm 80$ & \multirow{6}{*}{ [25] } \\
\hline FR-GFC (PVC) & 67.5 & - & " & " & \\
\hline GFC (stitch) & 90.0 & - & “ & “ & \\
\hline FR-GFC (stitch) & 180.0 & - & “ & “ & \\
\hline GFC (balsa) & 113.0 & - & “ & “ & \\
\hline FR-GFC (balsa) & 315.0 & - & “ & “ & \\
\hline Carbon-phenolic & - & 26.0 & “ & $"$ & \multirow{3}{*}{ [87] } \\
\hline Carbon-PEKK & - & 11.0 & “ & “ & \\
\hline Carbon-BMI & - & 28.0 & “ & “ & \\
\hline CFRP & 27.0 & - & “ & $" “$ & \multirow{5}{*}{ [29] } \\
\hline CFRP-GF & 30.0 & - & & & \\
\hline CFRP-TPCF & 26.0 & - & “ & “ & \\
\hline CFRP-TP & 34.0 & - & “ & “ & \\
\hline CFRP-Ti & 45.0 & - & “ & “ & \\
\hline Carbon/PPS & - & 80 & “ & “ & \multirow[t]{2}{*}{ [63] } \\
\hline Carbon/Epoxy & - & 68 & “ & “ & \\
\hline
\end{tabular}

HRR: heat release rate of the flame, ML: mass loss.

NexGen can simulate the fire condition specified by the FAA standard (ISO2685:1998 and AC20-135). However, according to Yi-Huan et al. (2017) [113], the current calibration criteria may not guarantee repeatability, necessitating the study of the sensitivity of performance of the burner to air and fuel flow rate, as measured by the temperature and heat flux for calibration purposes.

It was demonstrated that different burner operating settings might satisfy current calibration standards, resulting in differing outcomes during/after tests.

Using smaller thermocouples during calibration resulted in a test with less severe burner damage, allowing the test sample to survive longer.

Horold et al. [25] examined the fire stability of polymer composite materials in structural application. A large-scale fire test procedure under fully developed fire was applied to a series of glass fibre composites (GFCs) and a fire-retardant glass fibre composite (GFC-FR) with the dimensions of $500 \times 500 \times 24 \mathrm{~mm}$. Particularly, the effect was on the altered core structure (polyvinylchloride foam, polyisocyanurate foam reinforced with stitching the two skins together and balsa wood).

Some physical deformation of the composites was observed by Horold et al., such as cracks and delamination. The results obtained reveal that the fire resistance depends on the core material, which was able to prolong the time to failure by 2.1-3.4 times compared to the control sample. It was also observed that the core materials enhanced the performance even more than the flame retardants by a factor of 1.2-2.1; however, the intumescent flame 
retardant crucially improved the performance of each material, and the best result was achieved in the case of FR-GFC (stitched) (4.4 times the control sample).

The shell specimen that are representative of a typical carbon-reinforced polymer in modern civil aviation were exposed to a fully developed fire with direct flame impingement to one side at a heat flux of $182 \mathrm{~kW} / \mathrm{m}^{2}$. Sebastian et al. [24] looked at the time to failure of CFRP shells with and without flame-retarding designs. The unprotected CFRP specimens broke after only $27 \mathrm{~s}$, while the specimens with integrated protective layers that had low heat of conductivity and strong burn through resistance showed the best results. An integrated titanium foil decelerated the decomposition of the epoxy matrix and increased the time to failure by $68 \%$ compared to the unprotected CFRP shell.

Grange et al. [79] investigated the fire behaviour of three carbon-reinforced composites in a large-scale experiment. The carbon-polyetheretherketone (carbon/PEKK) composite has greater thermal stability, with less temperature variation and a moderate backside face temperature, according to their findings. Furthermore, these materials have a limited HRR value, which is up to five times lower than carbon-phenolic and three times lower than carbon-bismaleimide, limiting fire spread.

Eliot et al. [30] developed a kerosene flame test bench in order to analyse and compare the fire behaviour of composites mainly for aeronautic applications.

Two carbon-reinforced polymer composites based on thermosetting carbon/epoxy and thermoplastic carbon/polyphenylene sulphide with the same thickness and stacking sequence were studied. The results obtained revealed that the thermosetting-based laminate decomposed very fast and reached higher final temperature at the back face.

After $15 \mathrm{~min}$, the thermoplastic-based composite was not fully decomposed and a significant swelling was observed, which seems to induce an important thermal protection effect.

\section{Discussion}

This session presents the logical analysis of the main results from the various scales of the thermal and fire reaction facilities with respect to their significance in the assessment of fire risk and gas emission potentialities of the polymer composite materials reported.

The dynamic thermogravimetric tests at different heating rates and microcalorimeter combustion (MCC) can be used to examine the thermal degradation and fire behaviour of an unsaturated polyester resin containing phosphorus-based flame-retardant additives. Thus, it could be asserted that the fire risk property of the fire-retardant system is better than the non-flame-retardant system.

The TGA results of the thermal decomposition and stability of PLA modified with montmorillonites (cloisite 15 A, $20 \mathrm{~A}$ and $30 \mathrm{~B}$ ) revealed that the addition of the nanoparticles increased the char yield.

The heat release rate and total heat release of epoxy (EP) can be significantly reduced in the presence of micro-capsulated ammonium polyphosphate (MFAPP), as revealed by the MCC test. This could be attributed to the fact that MFAPP can induce the dehydration of EP at low temperature, and at a high temperature, it retards the pyrolysis of gases such as CO, hydrocarbon etc. The thermal oxidation and degradation of EP and EP/NPOSS composites have been characterised by DSC, TG, and FTIR. The mechanism of retardancy revealed that NPOSS formed a stable charred layer in the condensed phase [64]. Moreover, the flame retardancy and thermal stability of EP/MFAPP can be further improved in the presence of microcrystalline cellulose whiskers (MCW). The MCC test results at $6 \mathrm{wt} \%$ loading revealed a greater decrease in the HRR in the presence of whiskers compared with that of EP and EP/MFAPP.

The presence of a non-flammable flame retardant (FR) based on ammonium polyphosphate (APP) ester into a wood-plastic composite can reduce the HRR remarkably. A numerical value of $347 \mathrm{~kW} / \mathrm{m}^{2}$ can be obtained with the FR and a value of $311 \mathrm{~kW} / \mathrm{m}^{2}$ can be obtained with $10 \mathrm{wt} \%$ [11]. The results of the cone calorimeter test (CCT) revealed that the total smoke production (TSP) of carbon-reinforced epoxy composites depends on 
the thickness of the materials. The TSP for the specimen with a thickness of $4.2 \mathrm{~mm}$ is greater than that of $2.1 \mathrm{~mm}$. The smoke production rate (SPR) is inversely proportional to the number of layers of the carbon fibre plie.

The fire growth analysis (FIGRA) index is used to assess the fire risk of composite materials. The lower the value, the lower the fire hazard potential, i.e., the better the fire performance of the materials.

Compared with the cotton fibres, cotton/alginate blended fibres exhibited better fire performance properties due to the decrease in the total heat release (THR), peak of heat release rate (pHRR), total smoke production (TSP), and carbon dioxide production $\left(\mathrm{CO}_{2} \mathrm{P}\right)$.

From the results of the flame retardancy test of aluminium phosphinate (AlPi) incorporated into PPO, TPU, and PP, it can be asserted that the CCT, LOI, and UL-94 are significant bench-scale facilities for the assessment of the flammability and gas emission characteristics of the polymer. It is reported that glass-reinforced poly (1,4 butylene terephthalate) (GRPBT) composites have poor fire safety performance.

However, by the use of cone calorimeter and FTIR, the flammability and fire behaviour of GRPBT can be improved by incorporating an environmentally friendly flame retardant of trivalent metal ( $\mathrm{Al}, \mathrm{La}, \mathrm{Ce})$ into it.

Thus, the TSP of GRPBT/cerium hypophosphite composites can be reduced by $76 \%$ while the pHRR can be reduced by $44 \%$. The addition of $7.5 \mathrm{wt} \%$ APP and $2.5 \mathrm{wt} \%$ BPOPA into EP resin passed the UL-94 V-0 rating and has an LOI value of 33.1. In addition, much lower pHRR and TSP can be obtained [110].

The NexGen burner can simulate realistic fire conditions specified by the FAA standard (ISO 2685:1998 and AC 20-135).

The HRR of carbon/polyetherketoneketone composites is five times less than that of carbon/phenolic and three times less than that of carbon/bismaleimide, which therefore limits the fire spread.

The thermoplastic-based composite exhibited a fire-proof property due to a significant swelling observed during the thermal decomposition process, thereby displaying a thermal protection effect.

Summarily, from the analysis of the different scales of facilities, it can be deduced that the small-scale test results of the thermal characterisation (TGA, MCC) (as showed in Table 2) revealed better understanding of the chemical interaction phenomena with respect to the test parameters measured. Thus, this makes it easier for numerical validation because of the availability of input data. However, the shortcoming is the inability to measure some pertinent fire parameters such as flame growth, time to ignition, the peak of heat release rate, etc.

The medium-scale test results on the other hand have the advantages of measuring the total heat release, the flame growth rate, time to ignition, the peak of heat release rate, and other very useful fire safety indicators (as revealed in Tables 3-6). Nevertheless, these fire test conditions are not the true representation of the real-life fire scenario that the composite materials may encounter during application in terms of a fire safety standards test, especially in the transport sector such as aircrafts and ships.

The large-scale state-of-the-art facility such as the NexGen burner involves numerous fire reactions occurring at the same time, which may be difficult to fully understand. However, the fire test conditions certify the FAA standards having a flame temperature of $1100 \pm 80^{\circ} \mathrm{C}$ and a heat release rate of $116 \pm 10 \mathrm{~kW} / \mathrm{m}^{2}$ (as showed in Table 7). Therefore, this would enhance the wide applications of polymer composite materials in industries where fire safety is of paramount importance.

In addition, the analysis of the gas emission behaviour of the polymer composite materials showed significant differences with respect to their chemical composition (this can be found in Tables 3-6).

The polymer composite composition of AlPi/TPU suggest higher gas risk compared to AlPi/PP having the total smoke release of $3029 \mathrm{~m}^{2} / \mathrm{m}^{2}$ and $2310 \mathrm{~m}^{2} / \mathrm{m}^{2}$, respectively. 
Rigid poly(urethane-isocyanurate) exhibits high emission risk due to the release of a high amount of $\mathrm{CO}$ (carbon monoxide), $\mathrm{HCl}$ (hydrochlroric acid), and hydrogen cyanide $(\mathrm{HCN})$.

The amount of smoke release and $\mathrm{CO}$ emission during the thermal degradation of carbon-reinforced epoxy resin and carbon-reinforced phenolic composites increased with increased fibre layers. However, the amount of CO released was found to be about six times higher for the phenolic matrix compared to the epoxy resin.

\section{Conclusions}

This review has successfully explored the application of the various classes of the thermal and combustion state-of-the-art facilities deployed for the evaluation of the flammability and thermal stability of polymer composites.

Summarily, the small-scale facilities (such as TGA, MCC, etc.) provide detailed understanding and mastery of the thermal reaction properties of the composites. While with the medium scale, extended fire reaction parameters, which are the key indicators of the fire safety performance such as the pHRR, THR, TTI, TSP, $\mathrm{CO} / \mathrm{CO}_{2}$, etc. can be determined.

However, the large-scale burner as recommended by safety-concerned organisations such as the FAA has the advantage of being a representative of the realistic fire condition, thereby providing more precise and reliable data during the combustion process.

Therefore, comparative studies of thermophysical and gaseous emission parameters between medium and large-scale plants can be conducted.

Furthermore, novel polymer composite materials, particularly from bio-sources (because of their environmental friendliness, economic concerns, and acceptable fire safety performance) could be designed and tested as a potential substitute for synthetic composites in the transportation sector.

In finality, this paper seeks to provide a new perspective that will encourage more research efforts in this scientific domain, especially at the large scale.

Author Contributions: Conceptualization, K.C. and N.G.; methodology, K.C. and B.M.; investigation, K.C., N.G., B.M. and R.O.; resources, R.O.; original draft preparation, R.O.; writing-review \& editing, K.C., N.G., B.M. and R.O.; supervision, K.C. and B.M. All authors have read and agreed to the published version of the manuscript.

Funding: This research receives no external funding.

Institutional Review Board Statement: Not applicable.

Informed Consent Statement: Not applicable.

Acknowledgments: The authors appreciate the support of petroleum technology development fund (PTDF) of the Federal Government of Nigeria for funding the PhD research.

Conflicts of Interest: There is no conflict of interest declared by the authors.

$\begin{array}{ll}\text { Abbreviations } \\ \text { CCT } & \text { Cone calorimeter test } \\ \text { LOI } & \text { Limiting oxygen index } \\ \text { TGA } & \text { Thermogravimetric analysis } \\ \text { UL-94 } & \text { Underwriters' Laboratory } \\ \text { SPR } & \text { Smoke production rate } \\ \text { PEKK } & \text { Polyetherketoneketone } \\ \text { BMI } & \text { Bismaleimide } \\ \text { FAA } & \text { Federal Aviation Administration } \\ \text { NexGen } & \text { Next Generation } \\ \text { HCl } & \text { Hydrochloric acid } \\ \text { HCN } & \text { Hydrogen cyanide }\end{array}$




\section{References}

1. Fateh, T.; Kahanji, C.; Joseph, P.; Rogaume, T. A study of the effect of thickness on the thermal degradation and flammability characteristics of some composite materials using a cone calorimeter. J. Fire Sci. 2017, 35, 547-564. [CrossRef]

2. Didane, N.; Giraud, S.; Devaux, E.; Lemort, G. A comparative study of POSS as synergists with zinc phosphinates for PET fire retardancy. Polym. Degrad. Stab. 2012, 97, 383-391. [CrossRef]

3. Fina, A.; Bocchini, S.; Camino, G. Catalytic fire retardant nanocomposites. Polym. Degrad. Stab. 2008, 93, 1647-1655. [CrossRef]

4. Yang, W.; Tang, G.; Song, L.; Hu, Y.; Yuen, R.K. Effect of rare earth hypophosphite and melamine cyanurate on fire performance of glass-fiber reinforced poly(1,4-butylene terephthalate) composites. Thermochim. Acta 2011, 526, 185-191. [CrossRef]

5. Grange, N.; Chetehouna, K.; Gascoin, N.; Senave, S. Numerical investigation of the heat transfer in an aeronautical composite material under fire stress. Fire Saf. J. 2016, 80, 56-63. [CrossRef]

6. Zhao, B.; Liu, Y.-T.; Zhang, C.-Y.; Liu, D.-Y.; Li, F.; Liu, Y.-Q. A novel phosphoramidate and its application on cotton fabrics: Synthesis, flammability and thermal degradation. J. Anal. Appl. Pyrolysis 2017, 125, 109-116. [CrossRef]

7. Liu, Y.; Tao, Y.; Wang, B.; Li, P.; Xu, Y.-J.; Jiang, Z.-M.; Dong, C.-H.; Zhu, P. Fully bio-based fire-safety viscose/alginate blended nonwoven fabrics: Thermal degradation behavior, flammability, and smoke suppression. Cellulose 2020, 27, 6037-6053. [CrossRef]

8. Chen, X.; Feng, X.; Jiao, C. Combustion and thermal degradation properties of flame-retardant TPU based on EMIMPF6. J. Therm. Anal. Calorim. 2017, 129, 851-857. [CrossRef]

9. Yang, H.; Song, L.; Tai, Q.; Wang, X.; Yu, B.; Yuan, Y.; Hu, Y.; Yuen, K.K.R. Comparative study on the flame retarded efficiency of melamine phosphate, melamine phosphite and melamine hypophosphite on poly(butylene succinate) composites. Polym. Degrad. Stab. 2014, 105, 248-256. [CrossRef]

10. Barrow, C.S.; Lucia, H.; Stock, M.F.; Alarie, Y. Development of methodologies to assess the relative hazards from thermal decomposition products of polymeric materials. Am. Ind. Hyg. Assoc. J. 1979, 40, 408-423. [CrossRef]

11. Rashid, M.; Chetehouna, K.; Cablé, A.; Gascoin, N. Analysing flammability characteristics of green biocomposites: An overview. Fire Technol. 2021, 57, 31-67. [CrossRef]

12. Saba, N.; Jawaid, M.; Paridah, M.T.; Al-Othman, O.Y. A review on flammability of epoxy polymer, cellulosic and non-cellulosic fiber reinforced epoxy composites. Polym. Adv. Technol. 2015, 27, 577-590. [CrossRef]

13. Seefeldt, H.; Braun, U. A new flame retardant for wood materials tested in wood-plastic composites. Macromol. Mater. Eng. 2012, 297, 814-820. [CrossRef]

14. Wen, Y.; Cheng, Z.; Li, W.; Li, Z.; Liao, D.; Hu, X.; Pan, N.; Wang, D.; Hull, T.R. A novel oligomer containing DOPO and ferrocene groups: Synthesis, characterization, and its application in fire retardant epoxy resin. Polym. Degrad. Stab. 2018, 156, 111-124. [CrossRef]

15. Marquis, D.M.; Hermouet, F.; Guillaume, É. Effects of reduced oxygen environment on the reaction to fire of a poly (urethaneisocyanurate) foam. Fire Mater. 2016, 41, 245-274. [CrossRef]

16. Jian, R.-K.; Chen, L.; Chen, S.-Y.; Long, J.-W.; Wang, Y.-Z. A novel flame-retardant acrylonitrile-butadiene-styrene system based on aluminum isobutylphosphinate and red phosphorus: Flame retardance, thermal degradation and pyrolysis behavior. Polym. Degrad. Stab. 2014, 109, 184-193. [CrossRef]

17. Liang, W.-J.; Zhao, B.; Zhao, P.-H.; Zhang, C.-Y.; Liu, Y.-Q. Bisphenol-S bridged penta(anilino)cyclotriphosphazene and its application in epoxy resins: Synthesis, thermal degradation, and flame retardancy. Polym. Degrad. Stab. 2017, 135, 140-151. [CrossRef]

18. Wang, B.; Li, P.; Xu, Y.-J.; Jiang, Z.-M.; Dong, C.-H.; Liu, Y.; Zhu, P. Bio-based, nontoxic and flame-retardant cotton/alginate blended fibres as filling materials: Thermal degradation properties, flammability and flame-retardant mechanism. Compos. Part $B$ Eng. 2020, 194, 108038. [CrossRef]

19. Zhao, B.; Liu, D.-Y.; Liang, W.-J.; Li, F.; Wang, J.-S.; Liu, Y.-Q. Bi-phase flame-retardant actions of water-blown rigid polyurethane foam containing diethyl-N,N-bis(2-hydroxyethyl) phosphoramide and expandable graphite. J. Anal. Appl. Pyrolysis 2017, 124, 247-255. [CrossRef]

20. Ferry, L.; Dorez, G.; Taguet, A.; Otazaghine, B.; Lopez-Cuesta, J. Chemical modification of lignin by phosphorus molecules to improve the fire behavior of polybutylene succinate. Polym. Degrad. Stab. 2015, 113, 135-143. [CrossRef]

21. Gallo, E.; Schartel, B.; Schmaucks, G.; Von Der Ehe, K.; Böhning, M. Effect of well dispersed amorphous silicon dioxide in flame retarded styrene butadiene rubber. Plast. Rubber Compos. 2013, 42, 34-42. [CrossRef]

22. Shao, N.; Qu, Y.; Hou, L.; Hu, Y.; Tian, Z.; Gao, Y.; Zhu, X. Effect of starch-based flame retardant on the thermal degradation and combustion properties of reconstituted tobacco sheet. Cellulose 2020, 28, 741-755. [CrossRef]

23. Wu, K.; Zhang, Y.-K.; Zhang, K.; Shen, M.-M.; Hu, Y. Effect of microencapsulation on thermal properties and flammability performance of epoxy composite. J. Anal. Appl. Pyrolysis 2012, 94, 196-201. [CrossRef]

24. Fernández-Trujillo, F. SFPE Handbook of Fire Protection Engineering; Springer: New York, NY, USA; Dordrecht, The Netherlands; London, UK, 1386.

25. Hörold, A.; Schartel, B.; Trappe, V.; Korzen, M.; Bünker, J. Fire stability of glass-fibre sandwich panels: The influence of core materials and flame retardants. Compos. Struct. 2017, 160, 1310-1318. [CrossRef]

26. Timme, S.; Trappe, V.; Korzen, M.; Schartel, B. Fire stability of carbon fiber reinforced polymer shells on the intermediate-scale. Compos. Struct. 2017, 178, 320-329. [CrossRef] 
27. Ngan, A.; Jia, C.Q.; Tong, S.-T. Production, Characterization and Alternative Applications of Biochar; Springer: Singapore, 2019. [CrossRef]

28. Nartey, O.D.; Zhao, B. Biochar preparation, characterization, and adsorptive capacity and its effect on bioavailability of contaminants: An overview. Adv. Mater. Sci. Eng. 2014, 2014, 1-12. [CrossRef]

29. Yaashikaa, P.; Kumar, P.S.; Varjani, S.; Saravanan, A. A critical review on the biochar production techniques, characterization, stability and applications for circular bioeconomy. Biotechnol. Rep. 2020, 28, e00570. [CrossRef]

30. Klasson, K.T. Biochar characterization and a method for estimating biochar quality from proximate analysis results. Biomass Bioenergy 2017, 96, 50-58. [CrossRef]

31. Griffin, G.J. The effect of fire retardants on combustion and pyrolysis of sugar-cane bagasse. Bioresour. Technol. 2011, 102, 8199-8204. [CrossRef]

32. Zhou, S.; Ning, M.; Xu, Y.; Shu, J.; Wang, C.; Hu, Y.; Ge, S.; Tian, Z.; She, S.; He, Q. Effects of melamine phosphate on the thermal decomposition and combustion behavior of reconstituted tobacco sheet. J. Therm. Anal. Calorim. 2013, 112, 1269-1276. [CrossRef]

33. Kaya, H.; Ÿzdemir, E.; Kaynak, C.; Hacaloglu, J. Effects of nanoparticles on thermal degradation of polylactide/aluminium diethylphosphinate composites. J. Anal. Appl. Pyrolysis 2016, 118, 115-122. [CrossRef]

34. Ren, Y.; Wang, Y.; Wang, L.; Liu, T. Evaluation of intumescent fire retardants and synergistic agents for use in wood flour/recycled polypropylene composites. Constr. Build. Mater. 2015, 76, 273-278. [CrossRef]

35. Zhang, W.; Li, X.; Yang, R. Flame retardancy mechanisms of phosphorus-containing polyhedral oligomeric silsesquioxane (DOPO-POSS) in polycarbonate/acrylonitrile-butadiene-styrene blends. Polym. Adv. Technol. 2012, 23, 588-595. [CrossRef]

36. Pawlowski, K.H.; Schartel, B. Flame retardancy mechanisms of triphenyl phosphate, resorcinol bis (diphenyl phosphate) and bisphenol A bis (diphenyl phosphate) in polycarbonate/acrylonitrile-butadiene-styrene blends. Polym. Int. 2007, 56, $1404-1414$. [CrossRef]

37. Jiao, C.; Dong, J.; Chen, X.; Li, S. Influence of T31 content on combustion and thermal degradation behaviors on flame-retardant epoxy composites. J. Therm. Anal. Calorim. 2013, 114, 1201-1206. [CrossRef]

38. Xing, W.; Jie, G.; Song, L.; Wang, X.; Lv, X.; Hu, Y. Flame retardancy and thermal properties of epoxy acrylate resin/alphazirconium phosphate nanocomposites used for UV-curing flame retardant films. Mater. Chem. Phys. 2011, 125, 196-201. [CrossRef]

39. Xiao, F.; $\mathrm{Wu}, \mathrm{K}$. Influence of ionic liquid-based metal—Organic hybrid on thermal degradation, flame retardancy, and smoke suppression properties of epoxy resin composites. J. Mater. Sci. 2018, 53, 10135-10146. [CrossRef]

40. Li, B. Influence of polymer additives on thermal decomposition and smoke emission of poly(vinyl chloride). Polym. Degrad. Stab. 2003, 82, 467-476. [CrossRef]

41. Zhang, W.; Li, X.; Guo, X.; Yang, R. Mechanical and thermal properties and flame retardancy of phosphorus-containing polyhedral oligomeric silsesquioxane (DOPO-POSS)/polycarbonate composites. Polym. Degrad. Stab. 2010, 95, 2541-2546. [CrossRef]

42. Jiao, C.; Wang, H.; Chen, X.; Tang, G. Flame retardant and thermal degradation properties of flame retardant thermoplastic polyurethane based on HGM@[EOOEMIm][BF4]. J. Therm. Anal. Calorim. 2019, 135, 3141-3152. [CrossRef]

43. Schartel, B.; Patrick, M. Melamine poly(metal phosphates) as flame retardant in epoxy resin: Performance, modes of action, and synergy. J. Appl. Polym. Sci. 2016, 133, 43549. [CrossRef]

44. Vasile, M.N.C. Influence of the nanoparticle type on the thermal decomposition of the green starch/poly(vinyl alcohol)/montmorillonite nanocomposites. J. Therm. Anal. Calorim. 2013, 111, 1903-1919. [CrossRef]

45. Tirri, T.; Aubert, M.; Wilén, C.-E.; Pfaendner, R.; Hoppe, H. Novel tetrapotassium azo diphosphonate (INAZO) as flame retardant for polyurethane adhesives. Polym. Degrad. Stab. 2012, 97, 375-382. [CrossRef]

46. Allan, D.; Daly, J.; Liggat, J. Oxidative and non-oxidative degradation of a TDI-based polyurethane foam: Volatile product and condensed phase characterisation by FTIR and solid state 13C NMR spectroscopy. Polym. Degrad. Stab. 2019, 161, 57-73. [CrossRef]

47. Li, Z.; Cheng, X.; Shi, L.; He, S.; Gong, L.; Li, C. Flammability and oxidation kinetics of hydrophobic silica aerogels. J. Hazard. Mater. 2016, 320, 350-358. [CrossRef] [PubMed]

48. Borysiak, S.; Paukszta, D.; Helwig, M. Flammability of wood-polypropylene composites. Polym. Degrad. Stab. 2006, 91, 3339-3343. [CrossRef]

49. Liu, J.; Li, H.; Chang, H.; He, Y.; Zhong, A.; Wu, S.; Pan, B. Effect of water erosion on flame retardancy of high-impact polystyrene/magnesium hydroxide composite and its mode of action. Fire Mater. 2020, 44, 180-188. [CrossRef]

50. Tranchard, P.; Samyn, F.; Duquesne, S.; Thomas, M.; Estèbe, B.; Montès, J. Fire behaviour of carbon fibre epoxy composite for aircraft: Novel test bench and experimental study. J. Fire Sci. 2015, 33, 247-266. [CrossRef]

51. Chen, L.; Yang, Z.; Ren, Y.-Y.; Zhang, Z.-Y.; Wang, X.-L.; Yang, X.-S.; Yang, L.; Zhong, B. Fourier transform infrared spectroscopythermogravimetry analysis of the thermal decomposition mechanism of an effective flame retardant, hydroquinone bis(di-2methylphenyl phosphate). Polym. Bull. 2015, 73, 927-939. [CrossRef]

52. Ozdemir, E.; Lekesiz, T.O.; Hacaloglu, J. Polylactide/organically modified montmorillonite composites; Effects of organic modifier on thermal characteristics. Polym. Degrad. Stab. 2016, 134, 87-96. [CrossRef]

53. Gong, K.; Zhou, K.; Yu, B. Superior thermal and fire safety performances of epoxy-based composites with phosphorus-doped cerium oxide nanosheets. Appl. Surf. Sci. 2020, 504, 144314. [CrossRef] 
54. Mizera, K.; Kozikowski, P.; Leszczy, M.K. Synergistic effect between histidine phosphate complex and hazelnut shell for flammability reduction of low-smoke emission epoxy resin. Polym. Degrad. Stab. 2020, 181, 109292. [CrossRef]

55. Huang, H.; Dong, D.; Li, W.; Zhang, X.; Zhang, L.; Chen, Y.; Sheng, X.; Lu, X. Synergistic effect of MXene on the flame retardancy and thermal degradation of intumescent flame retardant biodegradable poly (lactic acid) composites. Chin. J. Chem. Eng. 2020, 28, 1981-1993. [CrossRef]

56. Costes, L.; Laoutid, F.; Aguedo, M.; Richel, A.; Brohez, S.; Delvosalle, C.; Dubois, P. Phosphorus and nitrogen derivatization as efficient route for improvement of lignin flame retardant action in PLA. Eur. Polym. J. 2016, 84, 652-667. [CrossRef]

57. Tranchard, P.; Duquesne, S.; Samyn, F.; Estèbe, B.; Bourbigot, S. Kinetic analysis of the thermal decomposition of a carbon fibre-reinforced epoxy resin laminate. J. Anal. Appl. Pyrolysis 2017, 126, 14-21. [CrossRef]

58. Fonseca, V.M.; Fernandes, V.J., Jr.; Araujo, A.S.; Carvalho, L.H.; Souza, A.G. Effect of halogenated flame-retardant additives in the pyrolysis and thermal degradation of polyester/sisal composites. J. Therm. Anal. Calorim. 2005, 79, 429-433. [CrossRef]

59. Chen, X.; Huo, L.; Jiao, C.; Li, S. Journal of analytical and applied pyrolysis TG-FTIR characterization of volatile compounds from flame retardant polyurethane foams materials. J. Anal. Appl. Pyrolysis 2013, 100, 186-191. [CrossRef]

60. Zhao, B.; Liang, W.-J.; Wang, J.-S.; Li, F.; Liu, Y.-Q. Synthesis of a novel bridged-cyclotriphosphazene flame retardant and its application in epoxy resin. Polym. Degrad. Stab. 2016, 133, 162-173. [CrossRef]

61. Wei, Y.; Lei, S.; Yuan, H. Comparative study on thermal decomposition and combustion behavior of glass-fiber reinforced poly (1,4-Butylene Terephthalate) composites containing trivalent metals (Al, La, Ce) hypophosphite. Polym. Compos. 2013, 34, 1832-1839. [CrossRef]

62. Petigny, S.; Bert, C. Thermal degradation and flammability of polyamide 11 filled with nanoboehmite. J. Therm. Anal. Calorim. 2017, 129, 1029-1037. [CrossRef]

63. Realinho, V.; Haurie, L.; Antunes, M.; Velasco, J.I. Thermal stability and fire behaviour of flame retardant high density rigid foams based on hydromagnesite-filled polypropylene composites. Compos. Part B Eng. 2014, 58, 553-558. [CrossRef]

64. Chen, L.; Luo, Y.; Hu, Z.; Lin, G.-P.; Zhao, B.; Wang, Y.-Z. An efficient halogen-free flame retardant for glass-fibre-reinforced poly(butylene terephthalate). Polym. Degrad. Stab. 2012, 97, 158-165. [CrossRef]

65. Li, H.; Ning, N.; Zhang, L.; Wang, Y.; Liang, W.; Tian, M. Different flame retardancy effects and mechanisms of aluminium phosphinate in PPO, TPU and PP. Polym. Degrad. Stab. 2014, 105, 86-95. [CrossRef]

66. Kausar, A. Synthesis and properties of novel polystyrene/polyurea and functional graphene-based nanocomposite foams. J. Cell. Plast. 2016, 53, 305-318. [CrossRef]

67. Grange, N.; Chetehouna, K.; Gascoin, N.; Coppalle, A.; Reynaud, I.; Senave, S. One-dimensional pyrolysis of carbon based composite materials using FireFOAM. Fire Saf. J. 2018, 97, 66-75. [CrossRef]

68. Schuhler, E.; Chaudhary, A.; Vieille, B.; Coppalle, A. Fire behaviour of composite materials using kerosene burner tests at small-scales. Fire Saf. J. 2021, 121, 103290. [CrossRef]

69. Kinsella, K.; Markham, J.R.; Nelson, C.M.; Burkholder, T.R.; Street, S. Thermal Decomposition Products of Fiberglass Composites: A Fourier Transform Infrared Analysis. J. Fire Sci. 1996, 15, 108-125. [CrossRef]

70. Wu, K.; Song, L.; Hu, Y.; Lu, H.; Kandola, B.; Kandare, E. Synthesis and characterization of a functional polyhedral oligomeric silsesquioxane and its flame retardancy in epoxy resin. Prog. Org. Coat. 2009, 65, 490-497. [CrossRef]

71. Wang, B.; Zhou, K.; Jiang, S.; Hu, Y.; Gui, Z. The application of transition metal molybdates (AMoO4, A = Co, Ni, Cu) as additives in acrylonitrile-butadiene-styrene with improved flame retardant and smoke suppression properties. Polym. Adv. Technol. 2014, 25, 1419-1425. [CrossRef]

72. Cheng, X.; Wu, J.; Li, Y.; Yao, C.; Yang, G. SEBS-based thermoplastic elastomers containing aluminum hypophosphite and melamine cyanurate: Thermal degradation, flame retardancy, and mechanical properties. J. Fire Sci. 2019, 37, 137-154. [CrossRef]

73. Gibson, A.G.; Wright, P.N.H.; Wu, Y.S.; Mouritz, A.P.; Mathys, Z.; Gardiner, C.P. Modelling Residual Mechanical Properties of Polymer Composites after Fire. Plast. Rubber. Compos. 2003, 32, 81-90. [CrossRef]

74. Xing, W.; Song, L.; Hu, Y.; Zhou, S.; Wu, K.; Chen, L. Thermal properties and combustion behaviors of a novel UV-curable flame retarded coating containing silicon and phosphorus. Polym. Degrad. Stab. 2009, 94, 1503-1508. [CrossRef]

75. Tran, P.; Nguyen, Q.T.; Lau, K. Fire performance of polymer-based composites for maritime infrastructure. Compos. Part B Eng. 2018, 155, 31-48. [CrossRef]

76. Huggett, C.; Levin, B.C. Toxicity of the pyrolysis and combustion products of poly(vinyl chlorides): A literature assessment. Fire Mater. 1987, 11, 131-142. [CrossRef]

77. Yu, Z.; Liu, J.; Zhang, Y.; Luo, J.; Lu, C.; Pan, B. Thermo-oxidative degradation behavior and fire performance of high impact polystyrene/magnesium hydroxide/microencapsulated red phosphorus composite with an alternating layered structure. Polym. Degrad. Stab. 2015, 115, 54-62. [CrossRef]

78. Zuo, X.; Song, H.; Shao, H.; Au, M.H.; Wei, T.; Guo, J. Effects of OMMT on the aging behaviors of halogen-antimony flame-retarded LGFPA6 composites: Flammability and thermal degradation kinetics. Thermochim. Acta 2017, 653, 32-42. [CrossRef]

79. Monti, M.; Camino, G. Thermal and combustion behavior of polyethersulfone-boehmite nanocomposites. Polym. Degrad. Stab. 2013, 98, 1838-1846. [CrossRef]

80. Manfredi, L.B.; Rodríguez, E.S.; Wladyka-Przybylak, M.; Vázquez, A. Thermal degradation and fire resistance of unsaturated polyester, modified acrylic resins and their composites with natural fibres. Polym. Degrad. Stab. 2006, 91, 255-261. [CrossRef] 
81. Kim, N.; Dutta, S.; Bhattacharyya, D. A review of flammability of natural fibre reinforced polymeric composites. Compos. Sci. Technol. 2018, 162, 64-78. [CrossRef]

82. Torrecillas, R. Thermal degradation of high performance of structure on polyimide thermostability. Polym. Degrad. Stab. 1996, 54, 267-274. [CrossRef]

83. Najmi, H.; Luche, J.; Rogaume, T. Thermal decomposition of multilayer honeycomb core laminate sandwich composite panels in cone calorimeter apparatus-Effect of the top decomposed layer. J. Compos. Mater. 2021, 55, 2349-2368. [CrossRef]

84. Tadini, P.; Grange, N.; Chetehouna, K.; Gascoin, N.; Senave, S.; Reynaud, I. Thermal degradation analysis of innovative PEKK-based carbon composites for high-temperature aeronautical components. Aerosp. Sci. Technol. 2017, 65, 106-116. [CrossRef]

85. Hurley, M.J.; Gottuk, D.; Hall, J.R.; Harada, K.; Kuligowski, E.; Puchovsky, M.; Torero, J.; Watts, J.M.; Wieczorek, C. SFPE Handbook of Fire Protection Engineering, 5th ed.; Springer: New York, NY, USA, 2016. [CrossRef]

86. Ricciardi, M.R.; Antonucci, V.; Giordano, M.; Zarrelli, M. Thermal decomposition and fire behavior of glass fiber-reinforced polyester resin composites containing phosphate-based fire-retardant additives. J. Fire Sci. 2012, 30, 318-330. [CrossRef]

87. Liu, X.; Salmeia, K.; Rentsch, D.; Hao, J.; Gaan, S. Journal of analytical and applied pyrolysis thermal decomposition and flammability of rigid PU foams containing some DOPO derivatives and other phosphorus compounds. J. Anal. Appl. Pyrolysis 2017, 124, 219-229. [CrossRef]

88. Vieille, B.; Coppalle, A.; Le Pluart, L.; Schuhler, E.; Chaudhary, A.; Rijal, B.; Alia, A.; Delpouve, N. Kerosene flame behaviour of $\mathrm{C} /$ PEKK composite laminates: Influence of exposure time and laminates lay-up on residual mechanical properties. Compos. Part B Eng. 2021, 222, 109046. [CrossRef]

89. Wang, D.; Wen, P.; Wang, J.; Song, L.; Hu, Y. The effect of defect-rich molybdenum disulfide nanosheets with phosphorus, nitrogen and silicon elements on mechanical, thermal, and fire behaviors of unsaturated polyester composites. Chem. Eng. J. 2017, 313, 238-249. [CrossRef]

90. Li, W.; Li, S.; Cheng, Z.; Hu, X.; Yang, W.; Yao, Y. The effect of flame retardant-modified sepiolite nanofibers on thermal degradation and fire retardancy of low-density polyethylene. J. Therm. Anal. Calorim. 2019, 138, 1011-1019. [CrossRef]

91. Feng, X.; Xing, W.; Song, L.; Hu, Y.; Liew, K.M. TiO2 loaded on graphene nanosheet as reinforcer and its effect on the thermal behaviors of poly(vinyl chloride) composites. Chem. Eng. J. 2015, 260, 524-531. [CrossRef]

92. Grange, N.; Manescau, B.; Chetehouna, K.; Gascoin, N.; Lamoot, L.; Coppalle, A.; Senave, S.; Reynaud, I. Fire resistance of carbon-based composite materials under both ideal and realistic normative configurations. Appl. Therm. Eng. 2019, $159,113834$. [CrossRef]

93. Babrauskas, V. Development of the cone calorimeter?A bench-scale heat release rate apparatus based on oxygen consumption. Fire Mater. 1984, 8, 81-95. [CrossRef]

94. Vahabi, H.; Longuet, C.; Ferry, L.; David, G.; Robin, J.-J.; Lopez-Cuesta, J.-M. Effect of aminobisphosphonated copolymer on the thermal stability and flammability of poly(methyl methacrylate). Polym. Int. 2012, 61, 129-134. [CrossRef]

95. Idumah, C.I. Emerging advancements in flame retardancy of polypropylene nanocomposites. J. Thermoplast. Compos. Mater. 2020, 1-40. [CrossRef]

96. Sun, Z.; Ma, Y.; Xu, Y.; Chen, X.; Chen, M.; Yu, J.; Hu, S. Thermal degradation and flammability behaviour of HDPE/EVA/EG composites. Polym. Polym. Compos. 2013, 21,307-314. [CrossRef]

97. Wu, K.; Yuan, M.S. Thermal degradation and intumescent flame retardation of cellulose whisker/epoxy resin composite. J. Therm. Anal. Calorim. 2011, 104, 1083-1090. [CrossRef]

98. Luo, H.; Yang, Y.; Cao, X.; Cai, X. Thermal degradation mechanism and flame retardancy of epoxy systems containing tris(3nitrophenyl) phosphine. J. Therm. Anal. Calorim. 2018, 132, 1629-1637. [CrossRef]

99. Olaitan, A.J.; Ufuoma, O.D.; King, G.D.; Rapheal, O. Production of A Safety Helmet Using Palm Kernel Fiber And Shell Particulates. Int. J. Eng. Sci. Invent. 2017, 6, 44-55.

100. Ramgobin, A.; Fontaine, G.; Bourbigot, S. Thermal degradation and fire behavior of high performance polymers. Polym. Rev. 2019, 59, 55-123. [CrossRef]

101. Saoudi, T.; Belouchrani, M.A. Effect of a Thermal Degradation on the Mechanical Behavior of a 5-Harness Satin Weave Carbon-PEEK; Springer International Publishing: Berlin/Heidelberg, Germany, 2018; Volume 2. [CrossRef]

102. McNeill, I.C. Thermal degradation of polymer blends. Dev. Polym. Degrad. 1977, 1, 171-204. [CrossRef]

103. Chattopadhyay, D.K.; Webster, D.C. Thermal stability and flame retardancy of polyurethanes. Prog. Polym. Sci. 2009, 34, 1068-1133. [CrossRef]

104. Levchik, S.V.; Weil, E.D. Thermal decomposition, combustion and flame-retardancy of epoxy resins?a review of the recent literature. Polym. Int. 2004, 53, 1901-1929. [CrossRef]

105. Spirckel, M.; Regnier, N.; Mortaigne, B.; Youssef, B.; Bunel, C. Thermal degradation and fire performance of newphosphonate polyurethanes. Polym. Degrad. Stab. 2002, 78, 211-218. [CrossRef]

106. Orhan, T.; Isitman, N.A.; Hacaloglu, J.; Kaynak, C. Thermal degradation mechanisms of aluminium phosphinate, melamine polyphosphate and zinc borate in poly(methyl methacrylate). Polym. Degrad. Stab. 2011, 96, 1780-1787. [CrossRef]

107. El Gouri, M.; El Bachiri, A.; Hegazi, S.E.; Rafik, M.; Elharfi, A. Thermal degradation of a reactive flame retardant based on cyclotriphosphazene and its blend with DGEBA epoxy resin. Polym. Degrad. Stab. 2009, 94, 2101-2106. [CrossRef] 
108. Ding, Y.; Swann, J.D.; Sun, Q.; Stoliarov, S.I.; Kraemer, R.H. Development of a pyrolysis model for glass fiber reinforced polyamide 66 blended with red phosphorus: Relationship between flammability behavior and material composition. Compos. Part B Eng. 2019, 176, 107263. [CrossRef]

109. Liu, J.; Guo, Y.; Zhang, Y.; Liu, H.; Peng, S.; Pan, B.; Ma, J.; Niu, Q. Thermal conduction and fire property of glass fiber-reinforced high impact polystyrene/magnesium hydroxide/microencapsulated red phosphorus composite. Polym. Degrad. Stab. 2016, 129, 180-191. [CrossRef]

110. Xing, W.; Song, L.; Wang, X.; Lv, X.; Hu, Y. Preparation, combustion, and thermal behavior of UV-cured epoxy-based coatings containing layered double hydroxide. Polym. Adv. Technol. 2011, 22, 1859-1864. [CrossRef]

111. Monti, M.; Hoydonckx, H.; Stappers, F.; Camino, G. Thermal and combustion behavior of furan resin/silica nanocomposites. Eur. Polym. J. 2015, 67, 561-569. [CrossRef]

112. Deng, C.; Yin, H.; Li, R.-M.; Huang, S.-C.; Schartel, B.; Wang, Y.-Z. Modes of action of a mono-component intumescent flame retardant MAPP in polyethylene-octene elastomer. Polym. Degrad. Stab. 2017, 138, 142-150. [CrossRef]

113. Zhu, Z.-M.; Wang, L.-X.; Dong, L.-P. Influence of a novel P/N-containing oligomer on flame retardancy and thermal degradation of intumescent flame-retardant epoxy resin. Polym. Degrad. Stab. 2019, 162, 129-137. [CrossRef] 